\title{
The Chloroplastic GrpE Homolog of Chlamydomonas: Two Isoforms Generated by Differential Splicing
}

\author{
Michael Schroda, ${ }^{\mathrm{a}, 1}$ Olivier Vallon, ${ }^{\mathrm{a}}$ Julian P. Whitelegge, ${ }^{\mathrm{b}}$ Christoph F. Beck, ${ }^{\mathrm{c}}$ and Francis-André Wollman ${ }^{\mathrm{a}}$ \\ a Institut de Biologie Physico-Chimique, Unité Propre de Recherche 1261, 13 rue Pierre et Marie Curie, 75005 Paris, France \\ b Department of Chemistry and Biochemistry, University of California Los Angeles, 405 Hilgard Avenue, Los Angeles, \\ California 90095 \\ c Institut für Biologie III, Universität Freiburg, Schänzlestrasse 1, D-79104 Freiburg, Germany
}

\begin{abstract}
In eubacteria and mitochondria, Hsp70 chaperone activity is controlled by the nucleotide exchange factor GrpE. We have identified the chloroplastic GrpE homolog of Chlamydomonas, CGE1, as an 26-kD protein coimmunoprecipitating with the stromal HSP70B protein. When expressed in Escherichia coli, CGE1 can functionally replace GrpE and interacts physically with DnaK. CGE1 is encoded by a single-copy gene that is induced strongly by heat shock and slightly by light. Alternative splicing generates two isoforms that differ only by two residues in the $\mathrm{N}$-terminal part. The larger form is synthesized preferentially during heat shock, whereas the smaller one dominates at lower temperatures. Fractions of both HSP70B and CGE1 associate with chloroplast membranes in an ATP-sensitive manner. By colorless native PAGE and pulse labeling, CGE1 monomers were found to assemble rapidly into dimers and tetramers. In addition, CGE1 was found to form ATP-sensitive complexes with HSP70B of $\sim 230$ and $\sim 120 \mathrm{kD}$, the latter increasing dramatically after heat shock.
\end{abstract}

\section{INTRODUCTION}

Hsp70 proteins represent a highly conserved, ubiquitous class of molecular chaperones characterized by a great deal of functional diversity (reviewed by Hartl, 1996; Bukau and Horwich, 1998). They protect other proteins from misfolding and aggregation, assist in the refolding of denatured proteins, and participate in the translocation of polypeptides across biological membranes. They play roles in DNA replication and in the autoregulation of the heat shock response, and they participate in the disassembly of protein complexes.

The underlying mechanism for this plethora of different functions is the ATP-dependent binding and release of stretches of 7 hydrophobic amino acids flanked by basic amino acids, a motif that occurs statistically every 36 amino acids in proteins (Rüdiger et al., 1997). This rather unspecific mechanism is regulated and recruited for highly specific functions by specialized cohort proteins. One class of these cohort proteins is characterized by the presence of a socalled J-domain, which mediates the interaction with Hsp70

\footnotetext{
1 To whom correspondence should be addressed. E-mail ms@bop5. biologie.uni-freiburg.de; fax 49-761-203-2601.

Article, publication date, and citation information can be found at www.plantcell.org/cgi/doi/10.1105/tpc.010202.
}

and at the same time stimulates Hsp70's ATPase activity (Wall et al., 1994). For example, via the J-domain, DnaJ recruits DnaK (the Hsp70 homolog of Escherichia coli) for protein folding (Szabo et al., 1994); Tim44 mobilizes mtHsp70 for protein import into mitochondria (Rassow et al., 1994; Horst et al., 1997); GLSA (gonidialess A) together with cytosolic Hsp70 induces unequal divisions of embryonic cells of Volvox carteri (Miller and Kirk, 1999); and the Arabidopsis AtA39 J-domain protein, in complex with the tospoviral $\mathrm{NSm}$ protein and cytosolic Hsp70, has been proposed to mediate the cell-to-cell movement of virus particles in plants (Soellick et al., 2000).

In addition to the $\mathrm{J}$-domain proteins, other cohort proteins are involved in the regulation of the reaction cycle of Hsp70. For cytosolic Hsp70/Hsc70, well-characterized examples of such regulators are Chip, Hip, and Bag-1. Chip decreases the ATPase activity of $\mathrm{Hsp} 70 / \mathrm{Hsc70}$ and inhibits the binding and refolding of substrates (Ballinger et al., 1999). Hip stabilizes the ADP-bound state of Hsc70 (Höhfeld et al., 1995), whereas Bag-1M acts as an ADP release factor for Hsp70/ Hsc70 (Gässler et al., 2001).

Hsp70s of prokaryotic origin are regulated by the GrpE protein, which accelerates the activity of $\mathrm{Hsp} 70$ by inducing the release of nucleotide (Liberek et al., 1991; Deloche and Georgopoulos, 1996; Miao et al., 1997) and substrate (Jordan and McMacken, 1995; Harrison et al., 1997; Mally and Witt, 2001). Although functionally similar, Bag-1M and GrpE are 
not homologous. GrpE homologs have been discovered in mitochondria, first in yeast (Bolliger et al., 1994; Ikeda et al., 1994; Laloraya et al., 1994) and later also in Neurospora (Voos et al., 1994), mammals (Naylor et al., 1996), and plants (Padidam et al., 1999). Because of the presence of a GrpE protein in cyanobacteria, the putative progenitors of today's chloroplasts, and because of the high similarity of chloroplastic Hsp70s with DnaK (Drzymalla et al., 1996), a GrpE homolog also was likely to exist in the chloroplast.

Although the Hsp70 systems in the cytosol and in mitochondria have been studied in great detail, little is known about those of the chloroplast (Boston et al., 1996). The Hsp70 isoforms Com70 and lap70, both of which are of eukaryotic origin, are associated with the chloroplast envelope and have been shown to be involved in protein import (Ko et al., 1992; Schnell et al., 1994; Kourtz and Ko, 1997). Evidence for the participation of stromal Hsp70 in the import process, as manifested for its relative in the mitochondrial matrix, is still lacking (Schleiff and Soll, 2000).

A few polypeptides have been shown to interact with stromal Hsp70. These are phytoene desaturase of Narcissus pseudonarcissus chromoplasts (Bonk et al., 1996), the Rieske ironsulfur protein (Madueño et al., 1993), and newly imported ferredoxin-NADP ${ }^{+}$reductase (Tsugeki and Nishimura, 1993). These examples point to a function of stromal Hsp70 in protein folding and/or multiprotein complex assembly. Our previous finding that the stromal HSP70B protein of Chlamydomonas functions in the protection of photosystem II from damage caused by illumination with excess light (Schroda et al., 1999) suggested that stromal Hsp70 also may be involved in the biogenesis, maintenance, and degradation of protein complexes in the thylakoid membrane.

To further elucidate the stromal Hsp70 chaperone system, we set out to identify its cohort proteins by means of coimmunoprecipitation and native gel electrophoresis. In this work, we present the identification and the molecular, biochemical, and functional characterization of the chloroplastic GrpE homolog using Chlamydomonas as a plant model organism.

\section{RESULTS}

\section{An $\sim 26-k D$ Protein Is the Major Interaction Partner of HSP70B in ATP-Depleted Stroma}

To identify proteins that interact specifically with HSP70B, we immunoprecipitated HSP70B from an ATP-depleted stromal fraction prepared from isolated Chlamydomonas chloroplasts using a polyclonal anti-HSP70B antibody coupled to protein A-Sepharose. When the concentration of ATP is low, the majority of HSP70B is expected to occur in the ADP state, exhibiting the highest affinity for substrate proteins (Beckmann et al., 1990) and for certain cochaper- ones such as GrpE (Zylicz et al., 1987; Bolliger et al., 1994) and Tim44 (Horst et al., 1997). Immunoprecipitation of HSP70B under these conditions led to the coprecipitation of a major protein of $\sim 26 \mathrm{kD}$ (Figure 1) and two minor proteins of $\sim 32$ and $\sim 48 \mathrm{kD}$ (Figure 1, asterisks). Immunoprecipitation of HSP70B was repeated several times, and coprecipitated proteins were blotted onto a polyvinylidene difluoride (PVDF) membrane and subjected to microsequencing by Edman degradation and mass spectrometry of tryptic digests. Only for the $\sim 26-k D$ protein was sufficient material recovered to permit the determination of the $\mathrm{N}$-terminal sequence $\mathrm{AAE}$ VAEA and the internal sequence (I/L)P(I/L)VDN-E-AR (dashes indicate non-identified amino acid residues).

\section{Cloning of a cDNA Encoding a Chloroplastic GrpE Homolog}

From the recently established Chlamydomonas expressed sequence tag (EST) library (Asamizu et al., 1999), an EST clone (accession number AV391963) was identified that

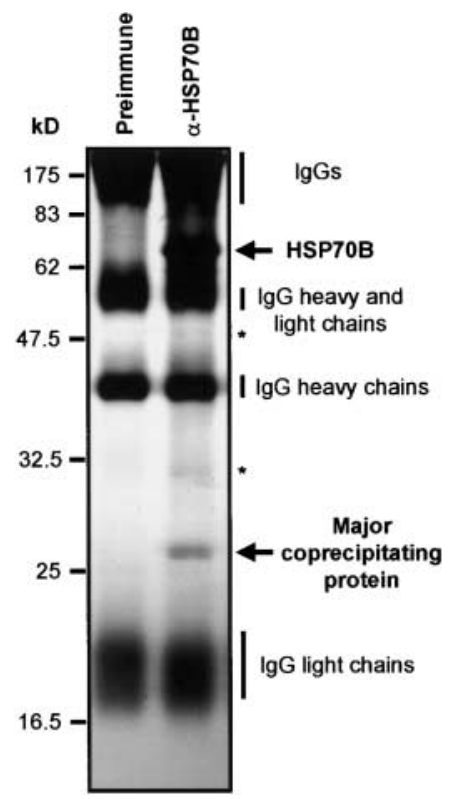

Figure 1. Immunoprecipitation of HSP70B.

Chlamydomonas chloroplasts were isolated and treated for $10 \mathrm{~min}$ with the uncoupler FCCP $(20 \mu \mathrm{M})$ before lysis and with apyrase (2 units $/ \mathrm{mL}$ ) after lysis to eliminate endogenous ATP. The soluble stroma fraction was incubated with protein A-Sepharose coupled to antibodies of either preimmune serum or anti-HSP70B serum $(\alpha-$ HSP70B). Precipitated proteins were separated on an SDS-12\% polyacrylamide gel and visualized by silver staining. Minor proteins of $\sim 32$ and $\sim 48 \mathrm{kD}$ coprecipitating with HSP70B are indicated by asterisks. 
contained peptide sequences matching those generated by microsequencing of the $26-\mathrm{kD}$ protein coprecipitating with HSP70B. This EST potentially coded for a GrpE-like protein. Because the likely ATG start codon was located only $5 \mathrm{bp}$ downstream of the $5^{\prime}$ end, this EST could not represent a full-length cDNA. Therefore, we isolated eight additional cDNAs from a cDNA library and sequenced two that, as judged from restriction digestion, exhibited the longest $5^{\prime}$ untranslated regions.

The most complete cDNA had a length of $1256 \mathrm{bp}$ with 31 bp of $5^{\prime}$ untranslated region, $774 \mathrm{bp}$ of coding region, and 451 bp of 3' untranslated region tailed by polyadenine (Figure 2). The high $\mathrm{G} / \mathrm{C}$ content of $66.5 \%$ of the coding region as well as the long $3^{\prime}$ untranslated region are typical features for Chlamydomonas genes (Harris, 1989). The surrounding of the first ATG start codon and of the TAA stop codon both fit almost exactly the Chlamydomonas consensus sequences, which are $(A / C) A(A / C)(A / C) A T G(G / C) C(C / G)$ and $(C / G) T A A(G / A)$, respectively (Silflow, 1998). Only the TGAAA sequence located 20 bp upstream of the polyadenine tail and most likely representing the polyadenylation signal is uncommon for Chlamydomonas genes, which normally have TGTAA at this position.

The cDNA potentially encodes a protein of 258 amino acids, of which the first 39 residues exhibit the characteristics typical for Chlamydomonas chloroplast targeting signals (Franzén et al., 1990). Also, these $39 \mathrm{~N}$-terminal residues are recognized as a potential chloroplast targeting signal by the ChloroP program (Emanuelsson et al., 1999), with a predicted cleavage site exactly where the $\mathrm{N}$-terminal sequence of the mature, coprecipitated protein starts (Figure 2). Thus, the mature protein would consist of 219 amino acids with a calculated molecular mass of $23.8 \mathrm{kD}$. It exhibits $32 \%$ identity and $52 \%$ similarity with the GrpE protein of $E$. coli and $31 \%$ identity and $49 \%$ similarity with Mge1p, the GrpE homolog of yeast mitochondria.

\section{The $\sim 26-k D$ Interaction Partner of HSP70B Is the Chloroplastic GrpE Homolog CGE1}

To verify that the $\sim 26-k D$ protein that interacts with HSP70B is in fact the GrpE-like protein encoded by the cDNA described above, we raised a polyclonal antibody against the 219 amino acids of the mature protein overexpressed in E. coli. Using this antibody, we were able to immunoprecipitate an $\sim 26-k D$ protein from ATP-depleted stromal fractions of Chlamydomonas chloroplasts and coprecipitated a major protein of $\sim 70 \mathrm{kD}$ (Figure 3). Immunoblotting revealed that the anti-GrpE antibody recognized the $\sim 26-\mathrm{kD}$ protein coimmunoprecipitated with anti-HSP70B antibodies, and vice versa, the anti-HSP70B antibodies recognized the $\sim 70-\mathrm{kD}$ protein coimmunoprecipitated with the anti-GrpE serum. We conclude that the $\sim 26-k D$ protein that interacts with HSP70B is the chloroplastic GrpE homolog CGE1, which is encoded by the cDNA we cloned.

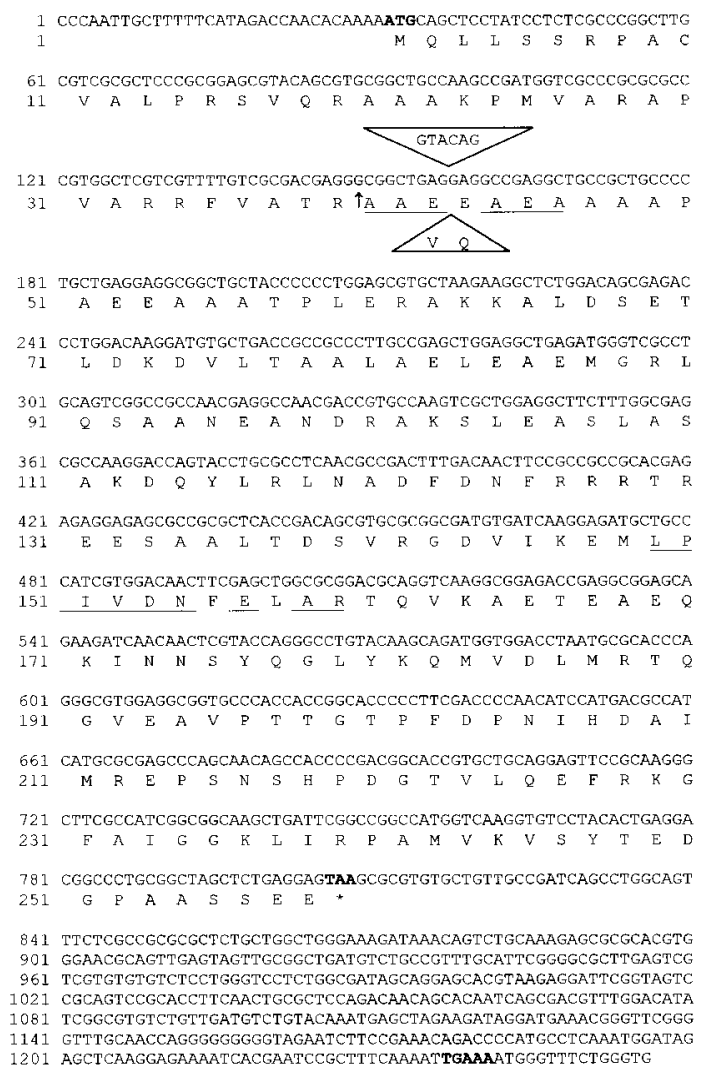

Figure 2. Nucleotide Sequence of the cDNA and Deduced Amino Acid Sequence of a Chloroplast-Targeted GrpE Homolog.

The ATG start codon, the TAA stop codon, and the putative polyadenylation signal TGAAA are shown in boldface, and the stop codon is indicated by an asterisk. Underlined sequences are an $\mathrm{N}$-terminal sequence and an internal peptide sequence generated by microsequencing. The sequence within the triangles is a 6-bp insertion giving rise to an additional valine $(V)$ and glutamine $(Q)$ residue found in one of the ESTs. The arrow indicates the cleavage site of the chloroplast targeting signal.

\section{CGE1 Is Encoded by a Single-Copy Gene That Is Inducible by Heat Shock and by Light}

The HSP7OB gene is inducible by heat shock and by a shift from dark to light, resulting in increased levels of both mRNA and protein (von Gromoff et al., 1989; Drzymalla et al., 1996). In E. coli, the GrpE protein is induced by heat stress (Ang et al., 1986), but this is not the case for its mitochondrial counterparts from yeast or rat (Ikeda et al., 1994; Naylor et al., 1996). To study the expression pattern of the CGE1 gene, we analyzed the accumulation of the CGE1 transcript in Chlamydomonas cells that had been shifted from 25 to $40^{\circ} \mathrm{C}$ or that had been shifted to the light after 15 $\mathrm{hr}$ of dark adaptation. In the experiment shown in Figure $4 \mathrm{~A}$ 


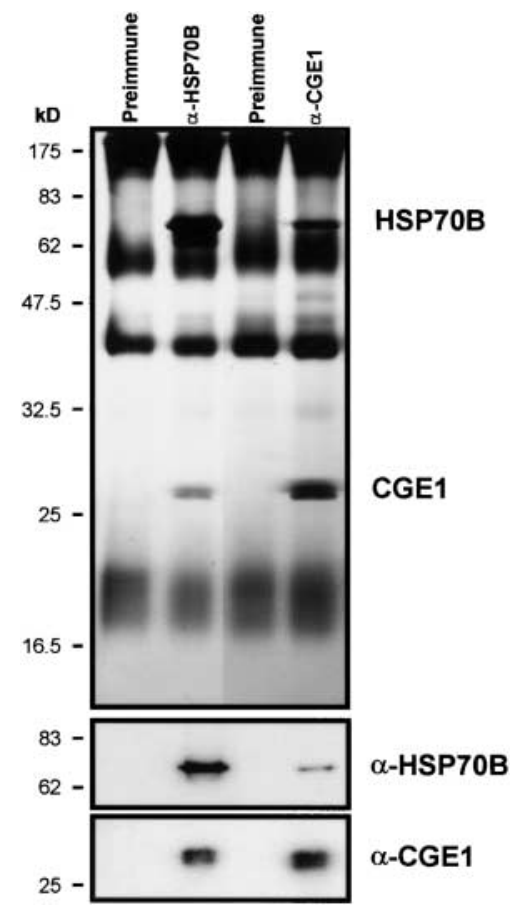

Figure 3. Coimmunoprecipitation of CGE1 and HSP70B.

ATP-depleted stromal fractions were incubated with antibodies against HSP70B and CGE1 ( $\alpha$-HSP70B and $\alpha$-CGE1) coupled to protein A-Sepharose, as described in Figure 1. Immunoprecipitated proteins were separated on an SDS-12\% polyacrylamide gel and visualized by silver staining (top gel) or blotted to nitrocellulose membranes (bottom gels). Membranes were immunodecorated with antiserum against HSP70B or CGE1, incubated with ${ }^{125}$-protein A, and exposed to a Phosphorimager screen.

(left), the CGE1 gene was induced $\sim 11$-fold with a maximum at $45 \mathrm{~min}$ after transfer to the increased temperature. When compared with $H S P 70 B$, which in the same experiment was induced $\sim 16$-fold, peaking 30 min after the shift, the induction of CGE1 upon heat shock was less pronounced and proceeded with retarded kinetics. Similar behavior was observed in the dark-to-light shift experiment (Figure $4 \mathrm{~A}$, right): whereas $H S P 70 B$ was induced $\sim 6$-fold with a peak 60 min after the onset of light, CGE1 was induced only $\sim 1.9$-fold, again exhibiting slightly retarded kinetics.

At the protein level, we observed a 2-fold increase in the concentration of HSP70B $90 \mathrm{~min}$ after the temperature change (see also Drzymalla et al., 1996), whereas for CGE1, a 1.8-fold increase was observed after $150 \mathrm{~min}$ at $40^{\circ} \mathrm{C}$ (Figure 4B). An increase in CGE1 after the dark-to-light shift, if any, was below the level of detection (data not shown).

As judged by immunoblotting (Figures 3 and $4 \mathrm{~B}$ ), the CGE1 protein accumulated as a double band. To test the possibility that CGE1 might be encoded by a gene family, we digested total DNA from Chlamydomonas with several restriction enzymes and hybridized a DNA gel blot with a probe directed against the coding region of CGE1 (Figure 4C). For any enzyme used, we observed a single band, except for Pstl and Ncol, for which restriction sites are present within the CGE1 coding sequence. We conclude that CGE1 is present as a single-copy gene in Chlamydomonas and that the two CGE1 isoforms most likely are derived either from post-transcriptional or post-translational modifications.

\section{CGE1 Is Present in Two Isoforms Generated by Alternative Splicing}

To determine whether the occurrence of two immunoreactive bands for CGE1 was attributable to post-translational modification, we pulse labeled nucleus-encoded heat shock proteins during heat shock and immunoprecipitated CGE1 at various times during chase. Clearly, the two isoforms were present immediately after the 12-min pulse and their ratio did not change during a 2-hr chase period, suggesting that they did not arise by a post-translational modification (data not shown).

To characterize the nature of the difference between the two CGE1 isoforms, we immunoprecipitated CGE1 from Chlamydomonas total soluble protein and subjected it to electrospray ionization mass spectrometry (ESI-MS). Transformation of the mass-charge profile into molecular mass revealed two peaks of approximately equal intensity (Figure $5 A$ ). The heterogeneity within the two peaks (i.e., the increase in mass in steps of 23 and $28 \mathrm{D}$ ) probably is caused by formylation of the protein that results from resuspending it in formic acid before ionization. The nonformylated, lower molecular mass form of CGE1 had a mass of 23,814.8 D (Figure 5A), which differs from its calculated mass of $23,812.5$ by only $2.3 \mathrm{D}$. The accuracy of our mass determination by ESI-MS is $\pm 0.01 \%$ (i.e., $2.4 \mathrm{D}$ for a $24-\mathrm{kD}$ protein).

The mass of the nonformylated, higher molecular mass form of CGE1 was 24,042.0 D, which is 227.2 D larger than its counterpart of lower molecular mass. The reason for this heterogeneity became clear when we considered the available EST and cDNA sequences. One of the ESTs (accession number AV391963) exhibits an insertion of 6 bp (GTACAG) after position 157 of the cDNA sequence displayed in Figure 2. As a result, the mature $\mathrm{N}$-terminal sequence is changed from $A A E E A E A$, found in the five other cDNA clones, to AAEVQEAEA. Both again differ slightly from the amino acid sequence generated by microsequencing (AAEVAEA). The molecular mass of a valine-plus-glutamine adduct is 227.13 $D$, which accounts perfectly for the mass difference of the two CGE1 isoforms determined by mass spectrometry. The presence of these two isoforms also explained the results of our initial $\mathrm{N}$-terminal sequencing: they must have yielded a mixture of valine $(\mathrm{V})$ and glutamate $(\mathrm{E})$ at cycle 3 and glutamine $(\mathrm{Q})$ and alanine $(A)$ at cycle 4 , which were interpreted as valine $(V)$ and alanine $(A)$, respectively, yielding AAEVAEA 
A
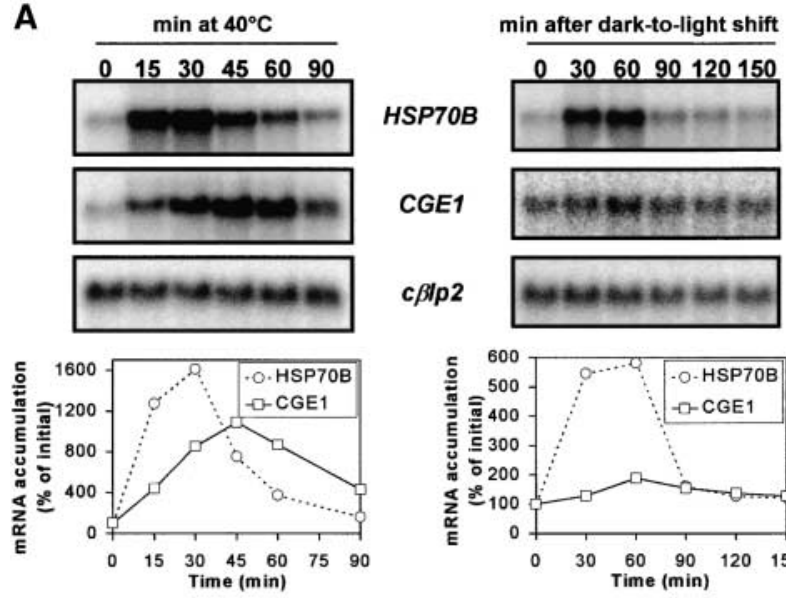

B

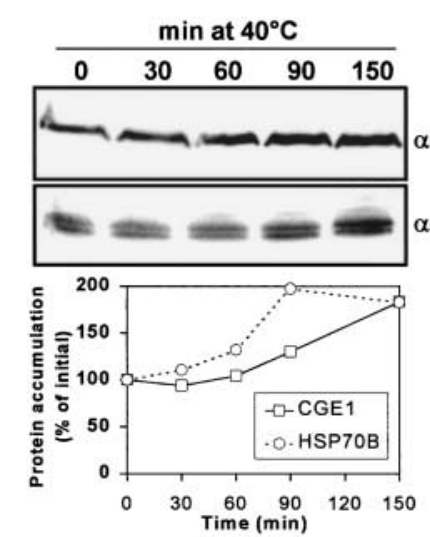

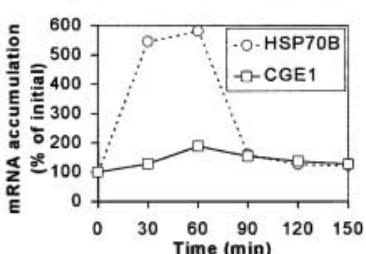

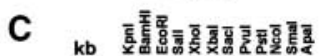

Figure 4. Induction Pattern of $H S P 7 O B$ and CGE1 mRNA and Protein and Analysis of the CGE1 Gene Copy Number.

(A) HSP7OB and CGE1 mRNA accumulation after a shift of cells from 25 to $40^{\circ} \mathrm{C}$ (left gels) and after a shift of cells grown for $15 \mathrm{hr}$ in the dark to light of $20 \mu \mathrm{E} \cdot \mathrm{m}^{-2} \cdot \mathrm{sec}^{-1}$ (right gels). RNA gel blots were hybridized with probes made of the coding regions of $H S P 70 B$, $C G E 1$, and the entire CDNA of the Chlamydomonas $\beta$-like protein 2 (c $\beta / p 2)$. Signals were quantified by phosphorimaging using $c \beta / p 2$ as a loading control.

(B) HSP70B and CGE1 protein accumulation after a shift of cells from 25 to $40^{\circ} \mathrm{C}$. Immunoblots were incubated with ${ }^{125}$-protein $A$, and signals were quantified by phosphorimaging.

(C) DNA gel blot analysis of Chlamydomonas total DNA digested with the restriction enzymes indicated. The blot was hybridized with a probe made of the coding region of CGE1.

as the sequencing result. We have named the two isoforms CGE1a and CGE1b for the short and long form, respectively.

Because only one gene was detected by DNA gel blot analyses, we imagined the possibility that the 6-bp polymor-

phism in the CGE1 mRNA was caused by alternative splicing of an intron situated at this position. Indeed, when we sequenced the corresponding region of the CGE1 gene amplified by polymerase chain reaction (PCR) from total Chlamydomonas DNA, we identified an intervening sequence precisely at the position of the polymorphism (Figure 5B). The intervening sequence was $100 \mathrm{bp}$ in length and contained two potential $5^{\prime}$ intron splice sites, both of them only partially matching the consensus sequence for $5^{\prime}$ splice sites derived from 266 Chlamydomonas introns (Silflow, 1998). We conclude that the accumulation of two different forms of mature CGE1 mRNA, and hence of the two isoforms of the CGE1 protein, results from the differential use of the two 5' splice sites by the spliceosome.

The smaller CGE1a isoform appeared to be more abundant under basal conditions (Figure 6A), whereas the larger CGE1b dominated after prolonged heat shock (Figure 4B). This finding suggested that the two CGE1 mRNAs may exist in different relative amounts in the cell, depending on changes in environmental conditions. To test this notion, we reverse transcribed the mRNA isolated for the experiment shown in Figure $4 \mathrm{~A}$ and used it as a template for PCR. With the primers indicated in Figure 5B, we expected amplification products of $79 \mathrm{bp}$ for CGE1a and 85 bp for CGE1b.

Quantification of the PCR products shown in Figure 5C, taking into account the incorporation of more label into the 85-bp fragment, revealed that CGE1a represented $\sim 60 \%$ of the CGE1 mRNA when cells were grown in the dark or in the light (Figure 5C). Upon dark-to-light shift, the contribution of CGE1a increased to $\sim 70 \%$ of the total CGE1 message. In contrast, CGE1b rapidly became dominant after heat shock and represented up to $\sim 73 \%$ of the CGE1 mRNA when cells were kept at $40^{\circ} \mathrm{C}$ for 90 min (Figure $5 \mathrm{C}$ ). In strain CF185, the contribution of CGE1a to the total CGE1 message declined even more dramatically, from $80 \%$ at $25^{\circ} \mathrm{C}$ to $30 \%$ after $40 \mathrm{~min}$ at $40^{\circ} \mathrm{C}$ (data not shown). These results were confirmed by digesting reverse transcriptase-mediated PCR products of the CGE1 5' part with BseRI, the recognition site of which (GAGGAG) is destroyed by the 6-bp insertion (data not shown).

\section{Determination of the Suborganellar Localization and Concentration of CGE1 and HSP70B}

During their function as part of the mitochondrial import machinery, $\sim 20 \%$ of the mitochondrial Hsp70 homolog and a small fraction of the mitochondrial GrpE homolog are associated with the mitochondrial inner envelope membrane (Rassow et al., 1994; Horst et al., 1997). To analyze the suborganellar localization of HSP7OB and CGE1, we isolated Chlamydomonas chloroplasts and prepared highly pure stromal and membrane fractions, which were either depleted of ATP by carbonyl cyanide p-(trifluoromethoxy) phenylhydrazone (FCCP)/apyrase treatment or supplemented with $1 \mathrm{mM}$ 
A

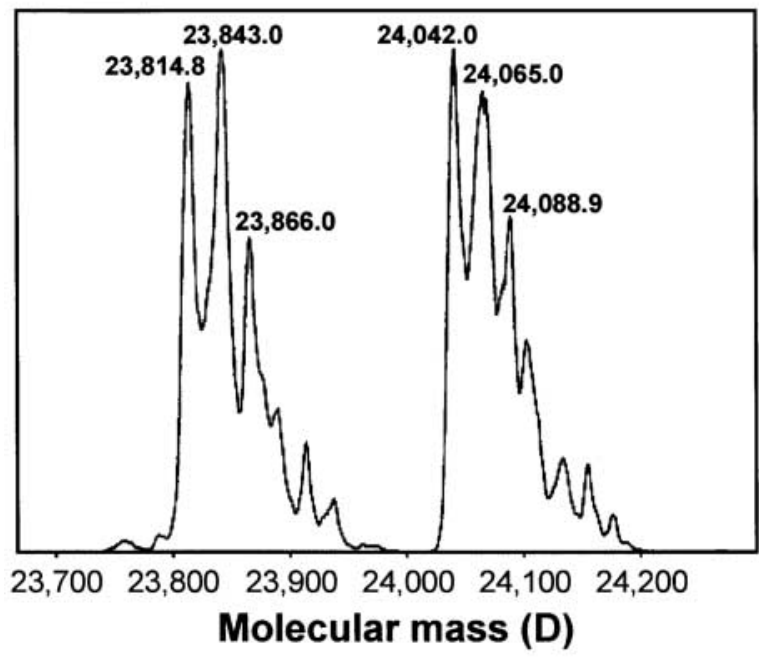

B
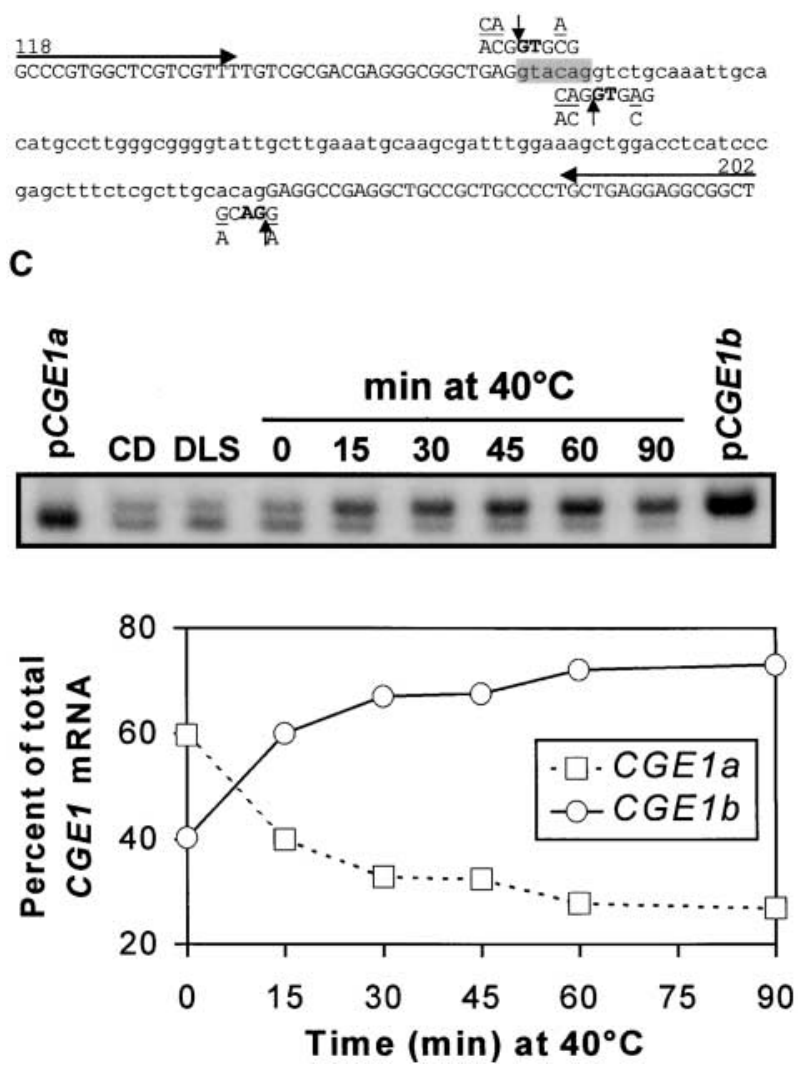

Figure 5. Analysis of the Nature of the Two CGE1 Isoforms.

(A) Mass determination of CGE1 by ESI-MS. Chlamydomonas total soluble proteins were incubated with anti-CGE1 antibodies coupled to protein A-Sepharose. Immunoprecipitated CGE1 was separated on an SDS-15\% polyacrylamide gel, blotted to a PVDF membrane, eluted, and analyzed by ESI-MS.
ATP. This was destined to increase or decrease, respectively, the stability of complexes involving HSP70B-CGE1 and membrane-associated substrate or partner proteins. As judged from the complete absence of the soluble ribulose1,5-bisphosphate carboxylase/oxygenase (Rubisco) protein from our membrane preparation and from the complete absence of the membrane-associated PETO protein (Hamel et al., 2000) from our stromal fraction, we could exclude nonspecific cross-contaminations (Figure 6A).

Whereas the majority of HSP70B and CGE1 was found in the stroma, a significant amount of both proteins also was detected in the membrane fraction (Figure 6A). Specifically, the amount of membrane-associated HSP70B and CGE1 was approximately five times higher in chloroplasts that had been depleted of ATP than in ATP-repleted chloroplasts. The slower migration of HSP7OB and PETO in the membrane fractions probably is attributable to the high sucrose content of these fractions. Apparently, the efficient sequestering of HSP70B and CGE1 to the membrane fraction of ATP-depleted chloroplasts led to a net loss of both proteins in the stroma of ATP-depleted chloroplasts relative to ATPrepleted chloroplasts. Similar results were obtained in two independent experiments.

Next, we determined the concentrations of HSP70B and CGE1 in the stroma. For this, we compared the immunoreactivity of an ATP-repleted stroma fraction with a standard curve obtained from His-tagged HSP70B and CGE1 purified from overexpressing $E$. coli strains (Figure 6B). As an average of two independent experiments, we determined that HSP70B represented $\sim 1.2 \%$ (1.7 and $0.6 \%$ ) of the stroma proteins, whereas this value was $\sim 0.07 \%$ ( 0.08 and $0.06 \%$ ) for CGE1. Thus, on a molar basis, there is approximately six times more HSP70B than CGE1 present in the stroma. The ratios of Hsp70 to GrpE reported in E. coli and mitochondria are between 3:1 and 9:1 (Neidhardt et al., 1984; Nakai et al., 1994; Voos et al., 1994; Naylor et al., 1996).

(B) Sequence of an intron (lowercase) and parts of the flanking exons (uppercase) of the CGE1 gene. The sequence shown is situated between base 118 and base 202 of the CGE1 cDNA of Figure 2. (C/ A)(A/C)G $\downarrow G T G(A / C) G$ and $(G / A) C A G \downarrow(G / A)$ are the Chlamydomonas consensus sequences for the $5^{\prime}$ and $3^{\prime}$ splice sites, respectively. The 6-bp sequence shaded in gray is present only in a fraction of CGE1 mRNAs. Arrows indicate the primers used for the reverse transcriptase-mediated PCR shown in (C).

(C) Reverse transcriptase-mediated PCR analysis of the two CGE1 mRNAs. Total RNA was isolated from Chlamydomonas cells kept for $15 \mathrm{hr}$ in the dark (CD), shifted for $90 \mathrm{~min}$ from dark to light of 20 $\mu \mathrm{E} \cdot \mathrm{m}^{-2} \cdot \mathrm{sec}^{-1}$ (DLS), grown at $25^{\circ} \mathrm{C}$ under continuous light, or heat shocked for $40 \mathrm{~min}$ at $40^{\circ} \mathrm{C}$. Reverse transcribed mRNA, or plasmid DNA containing cloned CGE1a or CGE1b cDNAs, was used as a template for a PCR including ${ }^{33} \mathrm{P}-\mathrm{dATP}$ and the primers depicted in (B). The PCR products of 85 and 79 bp were separated on a Trisborate/EDTA (TBE)-12\% polyacrylamide gel, which was dried and used for phosphorimaging. 
A

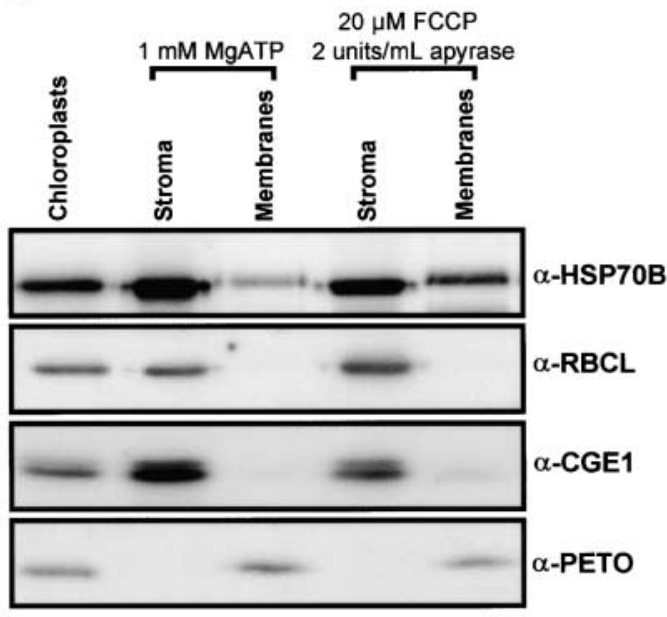

B

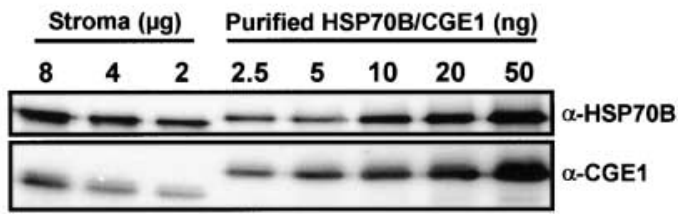

Figure 6. Determination of the Suborganellar Localization and the Concentration of HSP70B and CGE1.

(A) Fractionation of chloroplasts into stroma and membranes. Chlamydomonas chloroplasts were isolated to high purity, and onehalf was incubated with $20 \mu \mathrm{M}$ FCCP. Chloroplasts were lysed in the presence of 2 units $/ \mathrm{mL}$ apyrase or $1 \mathrm{mM}$ ATP and separated into stroma and membranes. Proteins were separated on an SDS-7.5 to $15 \%$ polyacrylamide gradient gel and blotted to a nitrocellulose membrane, which was immunodecorated with antiserum $(\alpha)$ against HSP70B, CGE1, the large subunit of Rubisco (RBCL), or the PETO protein of the cytochrome $b_{6} f$ complex. Immunoblots were incubated with ${ }^{125}$-protein $\mathrm{A}$, and signals were quantified by phosphorimaging.

(B) Determination of HSP70B and CGE1 concentrations in the stroma. Eight, 4, and $2 \mu \mathrm{g}$ of ATP-repleted stroma prepared as described in (A) were separated on an SDS-7.5 to 15\% polyacrylamide gradient gel next to the indicated amounts of double hexahistidinetagged $\mathrm{HSP} 70 \mathrm{~B}$ and $\mathrm{CGE} 1$ purified from overexpressing $E$. coli strains and blotted to nitrocellulose. The membrane was immunodecorated with antiserum $(\alpha)$ against HSP70B or CGE1 and incubated with ${ }^{125}$-protein $A$, and signals were quantified by phosphorimaging.

\section{ATP and ADP but Not GTP Efficiently Dissociate the HSP70B-CGE1 Complex}

The complex formed by the yeast mitochondrial GrpE and Hsp70 homologs has been shown to dissociate upon incubation with ATP, ADP, and GTP, with ATP being the most efficient (Bolliger et al., 1994; Nakai et al., 1994; Azem et al.,
1997; Miao et al., 1997). To determine whether these three nucleotides also were efficient in destabilizing the HSP70BCGE1 complex, we incubated equal fractions of immunoprecipitated HSP70B with a buffer containing $10 \mu \mathrm{M}$ ATP, $10 \mu \mathrm{M}$ ADP, $50 \mu \mathrm{M}$ GTP, or no nucleotide and analyzed the amount of eluted CGE1 compared with that remaining associated with HSP70B on the resin. In the experiment shown in Figure 7, $\sim 90 \%$ of CGE1 was eluted by ATP, whereas only $\sim 2 \%$ was eluted when no nucleotide was added. Incubation with ADP or GTP resulted in the release of $\sim 64$ and $\sim 20 \%$, respectively, of CGE1 from HSP70B. Note that the different migration of eluted CGE1 compared with resin-bound CGE1 was caused by different protein contents in the samples and not by a differential release of the CGE1a and CGE1b isoforms.

In an independent experiment, the HSP70B-CGE1 complex was dissociated completely by both $50 \mu \mathrm{M}$ ADP and 50 $\mu \mathrm{M}$ ATP, whereas $50 \mu \mathrm{M}$ GTP dissociated $\sim 10 \%$ of the complex (data not shown). We conclude that the efficiency of nucleotides to dissociate the HSP70B-CGE1 complex is ATP $>$ ADP $>>$ GTP, qualitatively resembling the nucleotide-dependent release observed for the yeast mitochondrial Hsp70-GrpE homologs.

\section{CGE1 Is Rapidly Assembled into a Dimer and Forms Complexes of $\sim 120$ and $\sim 230 \mathrm{kD}$ with HSP70B That Are Sensitive to ATP}

The E. coli GrpE protein and its yeast mitochondrial homolog Mge1p form homodimers, which may further oligomerize

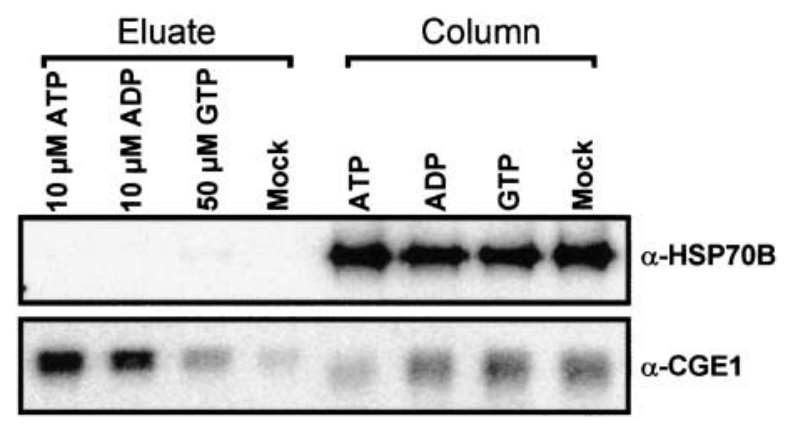

Figure 7. Effect of Nucleotides on the Dissociation of the HSP70BCGE1 Complex.

HSP70B-CGE1 complexes were immunoprecipitated from an ATPdepleted stromal fraction with HSP70B antibodies coupled to protein A-Sepharose as described in Figure 1 and, after washing, divided into four equal fractions. The fractions were incubated with elution buffer containing $10 \mu \mathrm{M}$ ATP, $10 \mu \mathrm{M}$ ADP, $50 \mu \mathrm{M}$ GTP, or no nucleotide (mock) for $15 \mathrm{~min}$ at $24^{\circ} \mathrm{C}$. Eluted proteins (eluate) and those remaining bound to the resin (column) were separated on an SDS-12\% polyacrylamide gel and blotted to nitrocellulose. Membranes were immunodecorated with antiserum $(\alpha)$ against HSP70B or CGE1 and incubated with ${ }^{125}$-protein $\mathrm{A}$, and signals were quantified by phosphorimaging. 


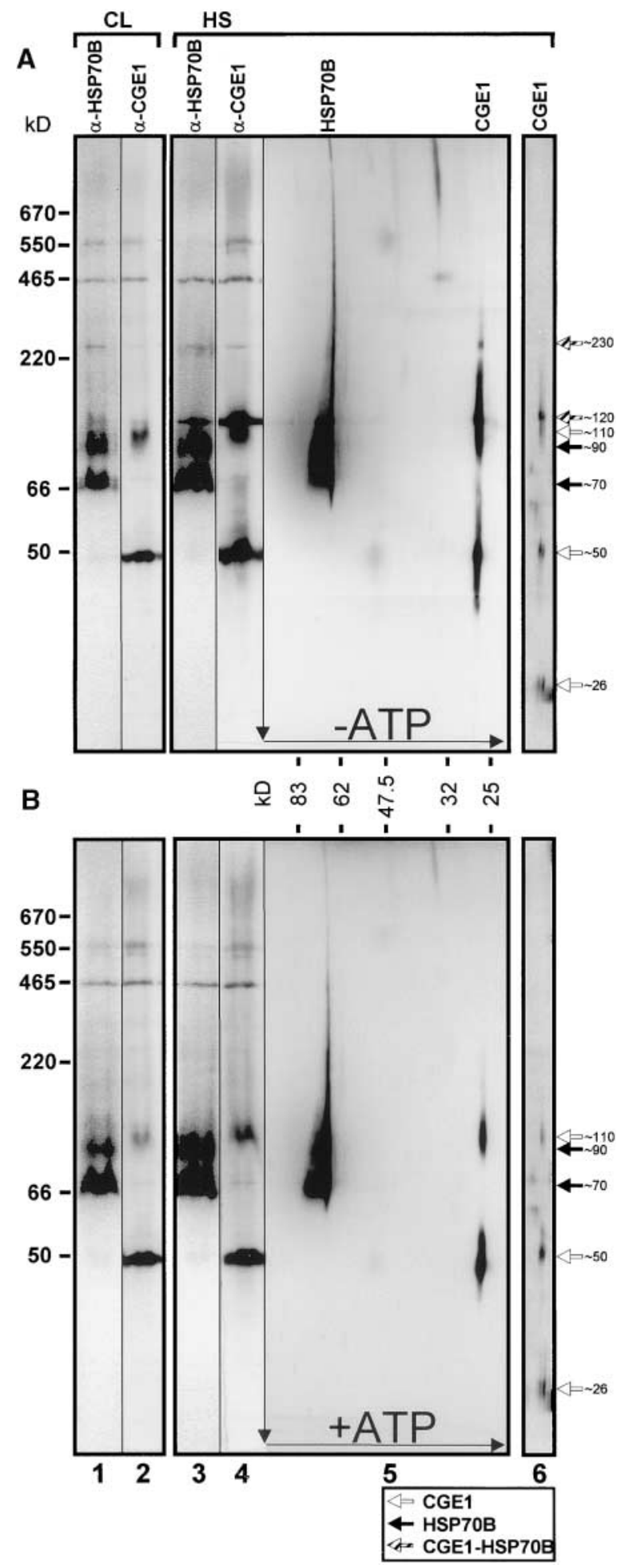

Figure 8. Analysis of Complexes Involving HSP70B and CGE1 by Two-Dimensional Gel Electrophoresis.

A Chlamydomonas culture was split into two fractions, one of which was left at $25^{\circ} \mathrm{C}$ in continuous light (CL; lanes 1 and 2), the other to tetramers, hexamers, etc. Stable complexes with DnaK or mtHsp70 are formed only with such dimers and oligomers, respectively (Deloche and Georgopoulos, 1996; Wu et al., 1996; Azem et al., 1997). To analyze the oligomerization states of CGE1, we separated whole cell soluble proteins by colorless native PAGE (CN-PAGE) (Schägger et al., 1994) in the first dimension and by SDS-PAGE in the second dimension. Before this, we pulse labeled nucleus-encoded proteins during heat shock with ${ }^{14} \mathrm{C}$-acetate to detect the oligomerization state of de novo synthesized CGE1. In addition, to allow the identification of complexes that are ATP sensitive, the experiment was performed with ATPdepleted (Figure 8A) and ATP-supplemented (Figure 8B) fractions.

By immunoblotting, most of CGE1 was detected in higher molecular mass complexes of $\sim 50, \sim 110, \sim 120$, and $\sim 230$ kD (Figure 8, lanes 2, 4, and 5). Only after long exposure times was it possible to visualize an $\sim 26-k D$ form corresponding to the monomeric CGE1a and CGE1b (data not shown). In contrast, the monomeric state of the two isoforms was detected easily after autoradiography of the same blot, which shows the ${ }^{14} \mathrm{C}$ incorporation during a 15min pulse under heat shock conditions (Figure 8, lanes 6). Thus, de novo synthesized CGE1a and CGE1b appear initially in their monomeric form and subsequently assemble into higher molecular mass complexes. Both CGE1 isoforms were synthesized during heat shock, with CGE1b being assembled slightly faster into the $\sim 50-, \sim 110-$, and $\sim 120-\mathrm{kD}$ complexes (Figure 8, lanes 6). The resolution of the native gel is not sufficient to determine whether they combine into homooligomeric or heterooligomeric complexes.

The complexes of $\sim 50$ and $\sim 110 \mathrm{kD}$ persisted also under ATP-repleted conditions (Figure 8B, lanes 2, 4, and 5); thus,

heat-shocked at $40^{\circ} \mathrm{C}$ for $55 \mathrm{~min}$ (HS; lanes 3 to 6). One-half of each fraction was supplemented with $20 \mu \mathrm{M}$ FCCP and 2 units $/ \mathrm{mL}$ apyrase (A), and the other half was supplemented with $1 \mathrm{mM} \mathrm{Mg-ATP}$ (B). To the heat-shocked fraction, $100 \mu \mathrm{g} / \mathrm{mL}$ chloramphenicol was added $30 \mathrm{~min}$ after the temperature shift, and a 15-min pulse labeling was performed by adding $10 \mu \mathrm{Ci} / \mathrm{mL}{ }^{14} \mathrm{C}$-acetate $40 \mathrm{~min}$ after the temperature shift for $15 \mathrm{~min}$. After sonication, soluble proteins were separated in the first dimension on a 6 to $18 \%$ native gel, transferred to nitrocellulose, and immunodecorated with antibodies $(\alpha)$ against HSP70B (lanes 1 and 3) and CGE1 (lanes 2 and 4). Alternately, gel strips were subjected to two-dimensional SDS-7.5 to $15 \%$ gradient gel electrophoresis and blotted. Before immunodetection with antibodies against HSP7OB and CGE1 (lanes 5), membranes were exposed to autoradiography (lanes 6). Only the region containing ${ }^{14} \mathrm{C}$-labeled CGE1 is displayed. Native marker proteins used were bovine thyroglobulin $(670 \mathrm{kD})$, the endogenous Rubisco $(550 \mathrm{kD})$, E. coli $\beta$-galactosidase $(465 \mathrm{kD})$, bovine liver catalase $(220$ $\mathrm{kD}), \mathrm{BSA}(66 \mathrm{kD})$, and potato apyrase $(50 \mathrm{kD})$. Black, white, and gray arrows indicate HSP7OB, CGE1, and complexes containing both proteins, respectively. 
they probably represent dimeric and tetrameric forms of CGE1, like those that have been described in eubacteria and mitochondria (Osipiuk et al., 1993; Schönfeld et al., 1995; Wu et al., 1996; Azem et al., 1997). In contrast, the complexes of $\sim 120$ and $\sim 230 \mathrm{kD}$ were absent under ATPrepleted conditions (cf. Figures $8 \mathrm{~A}$ and $8 \mathrm{~B}$ ). Because bands of $\sim 120$ and $\sim 230 \mathrm{kD}$ were detected reproducibly with antibodies against both HSP70B and CGE1, they probably represent heterooligomeric complexes consisting of both proteins (Figure 8A, lanes 1 to 4 ).

The large majority of HSP70B occurred in two forms of $\sim 70$ and $\sim 90 \mathrm{kD}$, which persisted as such independent of the presence of ATP (Figure 8, lanes 1, 3, and 5). In addition, a smear of HSP70B protein into the higher molecular mass region was detected that appeared to be reduced slightly in the presence of ATP (cf. lanes 5 of Figures $8 \mathrm{~A}$ and $8 \mathrm{~B}$ ). This may be caused by the interaction of HSP70B with other proteins either in vivo or during electrophoresis, leading to retarded migration.

The overall pattern of monomers and complexes of HSP70B and CGE1 in heat-shocked and non-heat-shocked cells was basically the same except that heat shock slightly increased the amount of HSP70B and CGE1 proteins (Figure 8 , cf. lanes 1 and 2 with lanes 3 and 4). Interestingly, heat shock led to a dramatic increase in the amount of the 120-kD HSP70B-CGE1 complex.

\section{CGE1 Complements the Temperature-Sensitive Phenotype of $E$. coli GrpE Mutants and Restores Their Ability to Replicate Phage $\boldsymbol{\lambda}$}

Previously, Deloche et al. (1997) have shown that the yeast mitochondrial GrpE homolog Mge1p was able to functionally replace GrpE of $E$. coli. To determine whether this was true for CGE1 as well, we transformed E. coli strain OD212 with a plasmid expressing the mature CGE1 protein with $\mathrm{N}$ - and $\mathrm{C}$-terminal hexahistidine tags or with the same plasmid expressing an unrelated protein. OD212 carries a deletion of its grpE gene, the normally lethal phenotype of which is suppressed by a mutation in the dnaK gene (dnaK332) (Deloche et al., 1997). The resulting phenotype is temperature-sensitive growth and the inability of this mutant to propagate phage $\lambda$.

As shown in Figure 9A, OD212 cells containing either the CGE1-expressing plasmid or the control plasmid grew equally well at $25^{\circ} \mathrm{C}$. However, cells harboring the control plasmid exhibited impaired growth already at $37^{\circ} \mathrm{C}$ and completely abolished growth at $43^{\circ} \mathrm{C}$, whereas those expressing CGE1 grew normally at these temperatures. In addition, CGE1-expressing cells were capable of replicating phage $\lambda$, although plaque number and plaque size were reduced compared with a wild-type $E$. coli strain (data not shown). In contrast, cells transformed with the control plasmid were incapable of phage $\lambda$ replication (data not shown).

The same results (i.e., complementation of temperature- sensitive growth and rescue of phage $\lambda$ propagation) were obtained for strain DA16 (data not shown), which carries the grpE280 mutation, resulting in mutant phenotypes similar to those exhibited by OD212 (Ang et al., 1986). In all of these experiments, CGE1 protein accumulation in OD212 was conferred only by leaky plasmidic expression and was comparable with the endogenous expression of CGE1 in Chlamydomonas (Figure 9B).

The functional replacement of $E$. coli GrpE by CGE1 implied a physical interaction of the latter with DnaK, the Hsp70 homolog of E. coli. To test for such an interaction, we affinity purified hexahistidine-tagged CGE1 overexpressed in $E$. coli under native conditions. Upon elution of CGE1, a prominent protein of $\sim 70 \mathrm{kD}$ coeluted, which by immunoblotting was identified as DnaK (Figure 9C). DnaK was

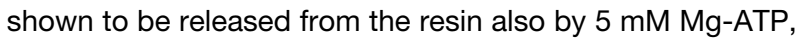
reflecting the specificity of its binding to CGE1. In contrast, elution of overexpressed, hexahistidine-tagged phage M13 gene 5 protein under native conditions did not coelute DnaK (Padidam et al., 1999). As observed in the crude lysates shown in Figure 9C, the overexpression of CGE1 also resulted in the overaccumulation of DnaK.

\section{DISCUSSION}

We report on the identification of the chloroplastic GrpE homolog of Chlamydomonas, termed CGE1, and on its biochemical and functional characterization. The following line of evidence led us to conclude that CGE1 is in fact the longsought chloroplastic GrpE homolog. First, as shown by coimmunoprecipitation experiments, CGE1 interacts directly with $\mathrm{HSP} 70 \mathrm{~B}$, the stromal Hsp70 homolog of Chlamydomonas. Second, the interaction of CGE1 with HSP70B is disrupted specifically by Mg-ATP. Third, CGE1 exhibits significant similarities to the GrpE protein of $E$. coli and to the yeast mitochondrial GrpE homolog Mge1p. Fourth, as judged from the complementation of $E$. coli grp $E$ mutants, CGE1 substitutes functionally for the GrpE protein of $E$. coli. In addition, it interacts physically in an ATP-dependent manner with DnaK, the Hsp70 homolog of $E$. coli. Fifth, the CGE1 gene encodes a protein with an N-terminal extension that is removed from the mature protein and shares the features of a typical Chlamydomonas chloroplast targeting sequence. Sixth, by fractionation experiments, the majority of CGE1 was shown to be localized in the chloroplast stroma.

In Figure 10, we aligned the deduced amino acid sequences of $E$. coli GrpE, of the mitochondrial GrpE homologs from a broad spectrum of organisms (mammals, insects, worms, fungi, and plants), of cyanobacterial GrpEs, of the CGE1 protein characterized in this work, and of a number of higher plant GrpE homologs. The latter were either identified in the Arabidopsis genome or deduced from assembled ESTs with high similarity to CGE1 (37 to $54 \%$ identity and 63 to $75 \%$ similarity). All of the latter contain $\mathrm{N}$-terminal extensions that 
A

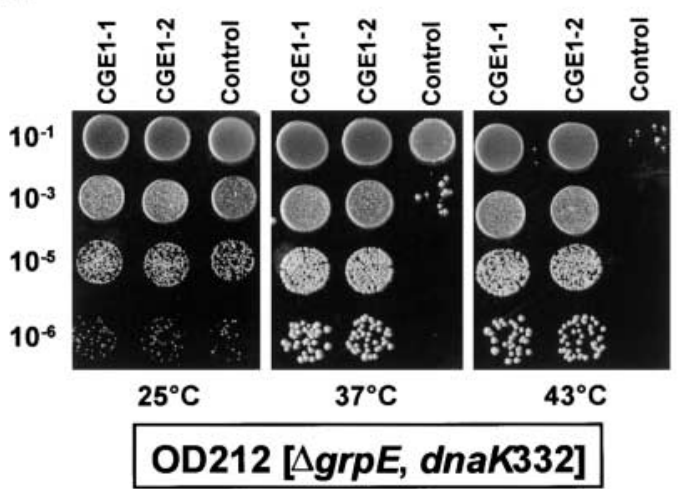

B

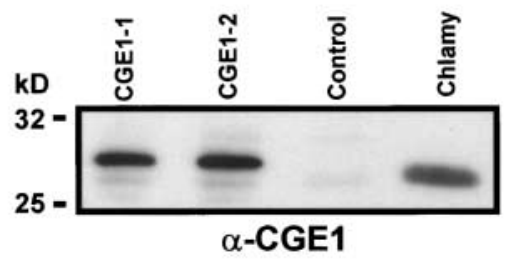

C

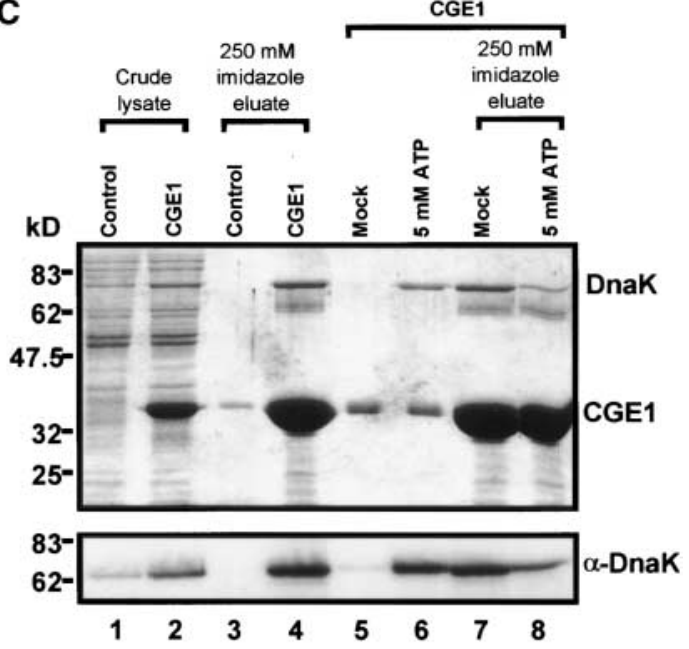

Figure 9. Complementation of the E. coli grpE Deletion Strain OD212 with CGE1 and Analysis of CGE1-DnaK Interactions.

(A) Temperature-sensitive $E$. coli strain OD212 carrying a deletion of its grpE gene was transformed with a plasmid vector for the expression of CGE1 (CGE1-1 and CGE1-2) or the same vector expressing an unrelated gene (control). Dilutions of transformant cultures were spotted onto Luria-Bertani plates and incubated overnight at 25, 37, or $43^{\circ} \mathrm{C}$.

(B) Comparison of the expression of CGE1 in the OD212 transformants described in (A) with Chlamydomonas (Chlamy) CGE1 by protein gel blot analysis and detection with CGE1 antiserum $(\alpha-$ CGE1). Each lane contained $15 \mu \mathrm{g}$ of total soluble protein.

(C) Expression of hexahistidine-tagged versions of CGE1 and an unrelated $30-\mathrm{kD}$ protein (control) from plasmid vectors was induced in the TargetP and Predotar programs predict with highest probability to be chloroplast targeting sequences (Emanuelsson et al., 1999).

From the alignment of these 19 GrpE sequences, we identified 18 amino acid residues that are conserved among all selected proteins, 12 that are found in the cyanobacterial/chloroplastic GrpE homologs but not in the mitochondrial homologs, and 12 that are found in the mitochondrial GrpE homologs but not in the cyanobacterial/chloroplastic homologs (Figure 10, residues highlighted in black, dark gray, and light gray, respectively).

When compared with 13 additional bacterial GrpE sequences (Naylor et al., 1996), only 5 residues among a total of 32 GrpE sequences were found to be strictly conserved. Furthermore, three residues (Y176, Y180, and R212) in Chlamydomonas CGE1 and one residue (F188) in yeast Mge1p were identified that occur exclusively in cyanobacterial/chloroplastic and mitochondrial GrpE homologs, respectively; therefore, they may provide specific signatures for these homologs (Figure 10, bottom line of alignment).

Previously, Wu et al. (1994) identified five distinct, highly conserved segments numbered I to $\mathrm{V}$ within bacterial and mitochondrial GrpE proteins. Because 5 of the 12 residues conserved among cyanobacterial/chloroplastic GrpE homologs, including the "signature" residues $Y 176$ and $Y 180$, are located within segment III and strongly perturb its conservation, the definition of segment III as highly conserved among all GrpE proteins appears obsolete. Segments I, II, IV, and V, however, are roughly maintained in the cyanobacterial/chloroplastic GrpE homologs and appear to be defined by the contact sites of the proximal GrpE monomer with Hsp70 (Figure 10).

With $80 \%$ identity and $91 \%$ similarity, the two plant mitochondrial GrpE homologs identified in tobacco appear to be closely related (Padidam et al., 1999), which also is the case for the two corresponding mitochondrial homologs we

E. coli strain M15 by isopropylthio- $\beta$-galactoside. Cells were lysed under native conditions (crude lysate; lanes 1 and 2) and incubated with nickel-nitrilotriacetic acid agarose (Ni-NTA). After washing, proteins bound to Ni-NTA were eluted by incubation with $250 \mathrm{mM}$ imidazole (lanes 3 and 4). In a parallel experiment, Ni-NTA beads binding CGE1 were first incubated for $10 \mathrm{~min}$ at $24^{\circ} \mathrm{C}$ with a buffer containing $20 \mathrm{mM}$ 3-( $\mathrm{N}$-morpholino)-propanesulfonic acid (Mops)$\mathrm{KOH}, \mathrm{pH} 7.4,80 \mathrm{mM} \mathrm{KCl}, 5 \mathrm{mM} \mathrm{MgCl}_{2}$, and either $5 \mathrm{mM}$ ATP or no nucleotide (mock) (lanes 5 and 6). The proteins that had remained on the resin then were eluted with $250 \mathrm{mM}$ imidazole (lanes 7 and 8). Eluted proteins were precipitated with trichloroacetic acid, separated on an SDS-10\% polyacrylamide gel, and visualized by Coomassie blue staining (top) or transferred to nitrocellulose and immunodetected with an antiserum $(\alpha)$ against DnaK using enhanced chemiluminescence (bottom). 

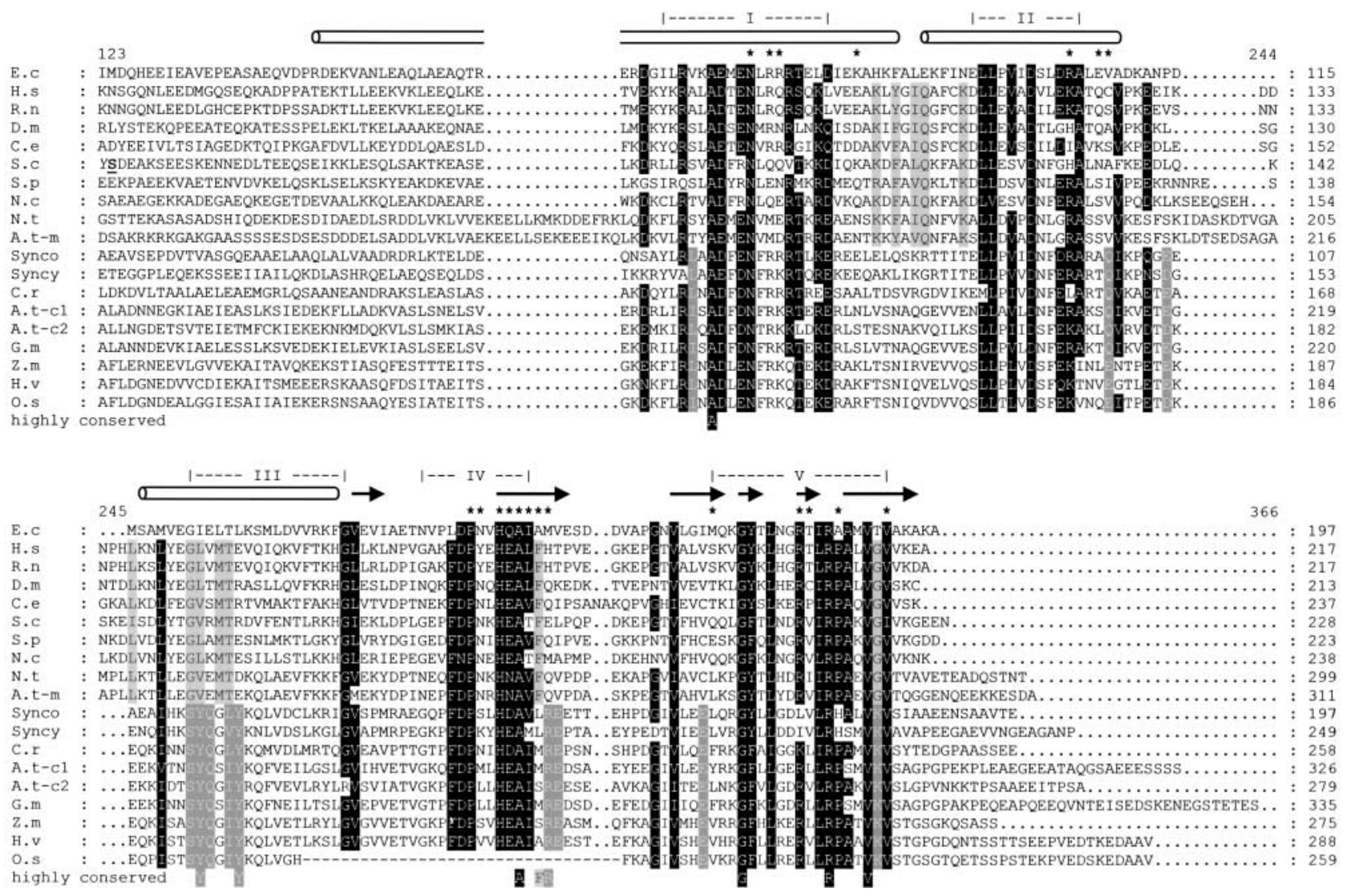

Figure 10. Alignment of GrpE Protein Sequences from Mitochondria, Cyanobacteria, and Chloroplasts of Various Organisms.

Aligned are deduced GrpE protein sequences from Escherichia coli (E.c; GenBank accession number P09372), Homo sapiens (H.s; AF298592), Rattus norvegicus (R.n; U62940), Drosophila melanogaster (D.m; U34903), Caenorhabditis elegans (C.e; Q18421), Saccharomyces cerevisiae (S.c; NC_001147), Schizosaccharomyces pombe (S.p; T40358), Neurospora crassa (N.c; AL355932), Nicotiana tabacum mitochondrial (N.t; AF098636), Arabidopsis thaliana mitochondrial (A.t-m; AL035440), Synechococcus sp PCC7942 (Synco; Q59984), Synechocystis sp PCC6803 (Syncy; Q59978), Chlamydomonas reinhardtii (C.r; AF406935), Arabidopsis thaliana chloroplastic 1 (A.t-c1; ATH010819), Arabidopsis thaliana chloroplastic 2 (A.t-c2; AC021199), Glycine max (G.m; assembled from ESTs BE609312 and BE658750), Zea mays (Z.m; assembled from ESTs AW355861 and Al665573), Hordeum vulgare (H.v; assembled from ESTs BF617074 and BE421818), and Oryza sativa (O.s; assembled from ESTs AU101207, C28419, and AU101208). Residues highlighted in black are conserved in at least $80 \%$ of all aligned GrpEs. Residues highlighted in light gray are conserved only in mitochondrial GrpEs, and those highlighted in dark gray are conserved only in chloroplastic/cyanobacterial GrpEs. Conserved amino acids were defined as $Q / N / D / E, R / K, S / T$, and V/I/L. Experimentally determined $N$ termini of mature proteins are shown in boldface, and their corresponding transit peptides are shown in italics. Gaps are indicated by dots, and missing residues in the Oryza sativa sequence are indicated by hyphens. Roman numerals indicate the highly conserved domains described by Wu et al. (1994). $\alpha$-Helices (cylinders), $\beta$-sheets (arrows), and contact sites (asterisks) of the proximal GrpE monomer with DnaK are drawn according to Harrison et al. (1997). Alignments were made with the ClustalW program, refined manually, and piled up by the GeneDoc program. 
found in the Arabidopsis genome (accession numbers AL035440 and AB010071). In contrast, the two putative Arabidopsis chloroplast GrpE homologs, both of which are expressed based on the presence of ESTs for each (accession numbers ATH010819 and AC021199), are approximately as distantly related to one another (46\% identical, $69 \%$ similar) as is CGE1 from Chlamydomonas to GrpE from Synechococcus. Therefore, we cannot exclude the possibility that a second chloroplastic GrpE homolog also exists in Chlamydomonas, which because of its expectedly low conservation with CGE1 was detected neither by DNA or RNA gel blotting nor by immunoblot analysis. In any case, the 14 Chlamydomonas ESTs coding for GrpE-like proteins identified so far in the database were derived from the CGE1 gene.

Previously, Schlicher and Soll (1997) reported the identification of a chloroplastic GrpE homolog from pea. In that work, a mainly stromal protein of $18 \mathrm{kD}$ was shown to crossreact with an antiserum raised against the GrpE protein of $E$. coli, which concomitantly also cross-reacted with the Rubisco small subunit. However, the same antiserum failed to cross-react with CGE1 coimmunoprecipitated with HSP70B, and conversely, our CGE1 antiserum did not detect GrpE from total $E$. coli protein (data not shown). In addition, the seven mature chloroplastic GrpE homologs shown in Figure 10 have calculated molecular masses between 24 and 29 $\mathrm{kD}$, whereas the smallest GrpE protein detected so far, from Lactococcus lactis (Naylor et al., 1996), has a mass of 20.4 kD. Because GrpE proteins generally migrate with apparent molecular masses $\sim 1$ to $2 \mathrm{kD}$ larger than their actual mass (Zylicz et al., 1987; Bolliger et al., 1994; Deloche and Georgopoulos, 1996; Padidam et al., 1999) (Figures 1, 3, 8, and 9 ), we consider it unlikely that the $18-\mathrm{kD}$ pea protein that cross-reacted with the $E$. coli GrpE antiserum was a bona fide GrpE homolog.

Chlamydomonas CGE1 exists as two isoforms of slightly different molecular mass produced by alternative splicing of the same pre-mRNA. The presence of two additional amino acid residues in the $\mathrm{N}$-terminal region of the longer CGE1b may endow it with slightly different properties. In this respect, it is notable that the CGE1a mRNA and protein are the most abundant under nonstress conditions, increasing even further upon dark-to-light shift (Figures 5C and 6A), whereas CGE1b message and protein become predominant after heat shock (Figures $4 \mathrm{~B}$ and $5 \mathrm{C}$ ). As judged from the two-dimensional gels (Figure 8 ), the two isoforms are able to multimerize and to associate with HSP70B, albeit with slightly different kinetics. It will be interesting to determine whether the CGE1 complexes formed under heat shock are homomultimers or heteromultimers and whether they have specific properties in terms of their affinity for HSP70B or of their efficiency in inducing nucleotide exchange or substrate release from HSP70B.

Crystal structure analysis has revealed that the $\mathrm{N}$ termini of the GrpE dimer bound to DnaK form a long parallel $\alpha$-helical structure that extends toward the peptide binding domain of DnaK (Harrison et al., 1997). Unfortunately, the GrpE variant used was truncated of its first $33 \mathrm{~N}$-terminal amino acids, so the structure of the region that differs between CGE1a and CGE1b is unknown. In contrast to wild-type GrpE, the truncated form was unable to induce the release of a model substrate bound to DnaK, suggesting that the first $33 \mathrm{~N}$-terminal residues of GrpE may interact with the substrate binding domain of DnaK. In support of this notion, wild-type GrpE was found to increase the rates of binding and release of substrates to the high affinity state of DnaK (Jordan and McMacken, 1995; Mally and Witt, 2001). We hypothesize that the CGE1b isoform containing the additional valine and glutamine residues near the $\mathrm{N}$ terminus may be more active in increasing the rates of substrate binding and release from $\mathrm{HSP} 70 \mathrm{~B}$, resulting in a higher refolding activity of this chaperone under heat shock conditions.

Therefore, the temperature dependence of splice site recognition would represent a regulator for the fine-tuning of the activity of the HSP70B chaperone machinery via CGE1. The mechanism that controls the differential splicing of the two forms in Chlamydomonas is unknown at present. It could result merely from a more efficient use of the distal 5' splice site by the spliceosome at increased temperatures, or it could be regulated by a factor specific to the heat shock response.

Although most of the HSP70B and CGE1 was localized to the stroma, a significant fraction of both proteins also was found to be membrane associated in an ATP-dependent manner: approximately fivefold more HSP70B and CGE1 was found in the membrane fraction of chloroplasts that had been depleted of ATP compared with ATP-repleted chloroplasts (Figure 6A). Because our membrane fraction contains both thylakoid and envelope membranes, several interpretations can be proposed.

An interaction of the HSP70B-CGE1 complex, particularly in the ADP state, with an inner membrane envelope protein, in analogy to mitochondria (Horst et al., 1997), may strongly suggest a function of this complex in protein import into the chloroplast. This interpretation is supported by recent studies that, on the basis of a computer algorithm, predict $\sim 75 \%$ of chloroplast transit peptides to contain potential binding sites for DnaK. Correspondingly, the transit peptide of the Rubisco small subunit has been shown to interact with DnaK (Ivey and Bruce, 2000; Ivey et al., 2000), and that of ferredoxin-NADP ${ }^{+}$reductase has been shown to interact with DnaK and CSS1, the stromal Hsp70 homolog of pea (Rial et al., 2000). However, direct evidence for a function of stromal Hsp70 in the import process is still lacking (Schleiff and Soll, 2000).

Alternately, as has been suggested for photodamaged photosystem II (Schroda et al., 1999), the HSP70B-CGE1 complex may interact with thylakoid membrane protein complexes, assisting in their proper assembly, maintenance, and degradation. In support of this idea, an association of the Synechococcus sp PCC7942 DnaK3-DnaJ7942 proteins with the cytosolic side of thylakoid membranes has been reported (Nimura et al., 1996; Oguchi et al., 1997). 
By analytical ultracentrifugation and glutaraldehyde cross-linking of purified proteins, both GrpE and its mitochondrial homolog mtGrpE have been shown to form homodimers of $\sim 40$ to $51 \mathrm{kD}$, which upon increasing protein concentrations were able to further oligomerize into tetramers, hexamers, and higher molecular mass oligomers $\mathrm{Wu}$ et al., 1996; Azem et al., 1997). The dimers can associate with DnaK and mitochondrial Hsp70, respectively, to form a heterooligomer of $\sim 116$ to 122 kD (Osipiuk et al., 1993; Schönfeld et al., 1995; Deloche and Georgopoulos, 1996; Wu et al., 1996; Azem et al., 1997). The concept of GrpE binding in a 2:1 stoichiometry to a DnaK monomer was corroborated by structural data (Harrison et al., 1997). However, an increase in the ratio of $\mathrm{mtGrpE}$ to $\mathrm{mtHsp} 70$ resulted in the formation of an additional complex of $\sim 240 \mathrm{kD}$ consisting of $\mathrm{mtGrpE}$ and $\mathrm{mtH} s \mathrm{sp}$, which was suggested to represent a dimer of mtHsp70-mtGrpE ${ }_{2}$ (Azem et al., 1997).

In this work, we used CN-PAGE (Schägger et al., 1994) combined with ${ }^{14} \mathrm{C}$-acetate pulse labeling, SDS-PAGE, and immunoblotting as an alternative approach to study complexes of CGE1 and HSP70B present in vivo. With this technique, we could show that the 26-kD monomeric CGE1 existed only as a short-lived species that was assembled rapidly into higher molecular mass complexes of $\sim 50$, $\sim 110, \sim 120$, and $\sim 230 \mathrm{kD}$ (Figure 8 ). The complexes of $\sim 120$ and $\sim 230$ kD comigrated with HSP70B and were dissociated by ATP, which was not the case for those of $\sim 50$ and $\sim 110 \mathrm{kD}$. Therefore, by analogy to the DnaK-GrpE and the mtHsp70-mtGrpE systems, we interpret the complex of $\sim 50 \mathrm{kD}$ as a CGE1 dimer and that of $\sim 110 \mathrm{kD}$ as a CGE1 tetramer. The $\sim 120-\mathrm{kD}$ complex most likely consists of a CGE1 dimer binding to monomeric HSP70B, and the complex of $\sim 230 \mathrm{kD}$ may represent either a dimer of HSP70B$\mathrm{CGE}_{1}$ or hexameric CGE1 binding to a HSP70B monomer. Under diffusion-limited conditions (size exclusion HPLC), which may prevail because of caging effects during electrophoresis in the native gel, a putative GrpE hexamer was shown to be the form that interacts most stably with DnaK (Wu et al., 1996).

Only in heat-stressed, ATP-depleted cells did we detect the $\sim 120-\mathrm{kD}$ HSP70B-CGE1 ${ }_{2}$ complex as a very abundant species (Figure 8 ). On the basis of the chaperone cycle proposed for DnaK (Bukau and Horwich, 1998), we interpret its formation as follows. Heat-denatured substrates either are bound directly by HSP70B present in the low-affinity, ATPbound state or delivered to HSP70B by a chloroplastic DnaJ homolog (Schlicher and Soll, 1997). Substrate binding induces ATP hydrolysis (Jordan and McMacken, 1995), leading to a ternary complex of ADP-HSP70B-substrate that, because of the presence of large amounts of unfolded polypeptides in the stroma, is present at a high concentration. Next, a CGE1 dimer binds the ternary ADP-HSP70Bsubstrate complex and induces the release of ADP (Liberek et al., 1991; Miao et al., 1997; Packschies et al., 1997) and substrate (Jordan and McMacken, 1995; Harrison et al., 1997; Mally and Witt, 2001). Sudden ATP depletion by treat- ment with FCCP and apyrase arrests the cycle at this point, because no more ATP is present to induce the release of the CGE1 dimer from HSP70B, eventually leading to the accumulation of a stable $\sim 120-\mathrm{kD}$ HSP7OB-CGE1 $1_{2}$ complex. The abundance of this complex after heat shock strongly suggests that it plays a major role in the refolding/prevention of aggregation of heat-denatured stromal proteins.

In addition to the $\sim 120$ - and $\sim 230-k D$ complexes, HSP70B was detected mainly as a monomer of $\sim 70 \mathrm{kD}$ and, in approximately equal amounts, as a higher molecular mass form of $\sim 90 \mathrm{kD}$ (Figure 8 ). As judged by its abundance, by its persistence in the presence of ATP, and by the lack of a prominent $\sim 20-\mathrm{kD}$ protein coprecipitating with HSP70B, the $\sim 90-k D$ species probably is not formed by the binding of a specific substrate or partner protein. Therefore, it is distinct from the Hsp70-Rieske protein complex of similar mass detected in native gels by Madueño et al. (1993). The $\sim 90-k D$ form appears to be specific for HSP70B, because DnaK purified from $E$. coli gives rise only to a single species on native gels (Buchberger et al., 1994). Possibly, it may arise from the binding of a nonproteinaceous compound to a fraction of HSP70B that significantly reduces its migration in native gels. The recent demonstration of the specific binding of sulfogalactolipids to the ATPase domain of a number of Hsp70 homologs provides an example of such a compound (Mamelak and Lingwood, 2001).

In conclusion, the chloroplast HSP70B-CGE1 chaperone system appears to share many properties with its eubacterial and mitochondrial counterparts, yet it has several unique characteristics. Both components are inducible by heat shock, which also shifts the balance between the two CGE1 isoforms in favor of CGE1b. They also are induced by a dark-to-light transition, which may indicate a role for HSP70B and mainly of CGE1a in the biogenesis of the photosynthetic apparatus and more generally in the development of the chloroplast. The complexes formed by HSP70B and CGE1 in vivo can be analyzed in great detail by $\mathrm{CN}$ PAGE, revealing previously unknown forms and stressing the role of the HSP70B-CGE $1_{2}$ complex in the refolding/ prevention of aggregation of heat-denatured chloroplast proteins.

\section{METHODS}

\section{Strains and Culture Conditions}

Chlamydomonas reinhardtii strain CF185 (Schroda et al., 1999) was used for all experiments except those described in Figures 4 and 5C, for which wild-type strain 137c $\left(\mathrm{mt}^{-}\right)$was used. Cells were grown mixotrophically in Tris-acetate-phosphate medium (Harris, 1989) on a rotatory shaker at $25^{\circ} \mathrm{C}$ at $\sim 30 \mu \mathrm{E} \cdot \mathrm{m}^{-2} \cdot \mathrm{sec}^{-1}$. For chloroplast isolation, cells were grown in Tris-acetate-phosphate medium supplemented with $0.5 \%$ peptone. Heat shock treatments and light induction were conducted as described previously (Schroda et al., 1999). 


\section{Chloroplast Isolation}

Light-grown cultures were placed in the dark overnight, reaching a density of 3 to $5 \times 10^{6} \mathrm{cells} / \mathrm{mL}$. Before harvest, cells were incubated in the light for $30 \mathrm{~min}$ and, except for the experiments shown in Figure 6 , heat shocked for $1 \mathrm{hr}$. All subsequent steps were performed at 0 to $4^{\circ} \mathrm{C}$. For each liter of culture, cells were resuspended in $25 \mathrm{~mL}$ of Neb buffer (0.3 M sorbitol, 50 mM Hepes-KOH, pH 7.2, 2 mM EDTA, and $1 \mathrm{mM} \mathrm{MgCl}_{2}$ ) and nebulized with the BioNebulizer (Glas-Col Apparatus Company, Terre Haute, IN). Nebulized material was collected by a brief centrifugation, and the pellet was resuspended in $2.5 \mathrm{~mL}$ of Neb buffer, layered onto a $45 / 70 \%$ Percoll step gradient, and centrifuged in a swinging-bucket rotor for $20 \mathrm{~min}$ at $4^{\circ} \mathrm{C}$ and $3500 \mathrm{~g}$. Intact chloroplasts were collected from the interphase, diluted fivefold with Neb buffer, and pelleted by a brief centrifugation. Chloroplasts were resuspended in Neb buffer and kept on ice.

\section{Chloroplast Fractionation}

Isolated chloroplasts were subjected to a second centrifugation on a $45 / 70 \%$ Percoll step gradient as described above and, after diluting out the Percoll, resuspended in Neb buffer. Two equal fractions, one of which was supplemented with $20 \mu \mathrm{M}$ carbonyl cyanide $\mathrm{p}$-(trifluoromethoxy) phenylhydrazone (FCCP), were agitated carefully at $25^{\circ} \mathrm{C}$ for $10 \mathrm{~min}$. Chloroplasts were pelleted and lysed by pipetting 20 times up and down with a 1-mL Gilson pipette in hypoosmotic lysis buffer ( $10 \mathrm{mM}$ Hepes, pH 7.4, 10 mM EDTA, 0.1 mM phenylmethylsulfonyl fluoride [PMSF], $0.5 \mathrm{mM} \varepsilon$-aminocaproic acid, and $0.1 \mathrm{mM}$ benzamidine). The FCCP-treated fraction was supplemented with 2 units $/ \mathrm{mL}$ apyrase, and the untreated fraction was supplemented with $1 \mathrm{mM}$ ATP and $20 \mathrm{mM} \mathrm{MgCl}_{2}$. Lysates were layered onto a cushion of $0.6 \mathrm{M}$ sucrose in hypoosmotic lysis buffer and centrifuged in a SW-41 rotor (Beckman, Palo Alto, CA) for $15 \mathrm{~min}$ at 300,000 g and $4^{\circ} \mathrm{C}$. The supernatant was saved as the stroma fraction.

Pelleted membranes were resuspended with a potter in $1.8 \mathrm{M}$ sucrose in hypoosmotic lysis buffer, onto which $1.3 \mathrm{M}$ sucrose in the same buffer was layered. Membranes were collected from the interphase after centrifugation for $2 \mathrm{hr}$ at $300,000 \mathrm{~g}$ and $4^{\circ} \mathrm{C}$.

\section{Coupling of Antibodies to Protein A-Sepharose}

Protein A-Sepharose (Sigma-Aldrich, St. Quentin Fallavier, France) was rehydrated in $0.1 \mathrm{M}$ phosphate buffer, $\mathrm{pH} 7.5$, for $30 \mathrm{~min}$ and washed three times in the same buffer. The swollen Sepharose was diluted with 2 volumes of $0.1 \mathrm{M}$ phosphate buffer. One volume of Sepharose solution was mixed with two volumes of antiserum and incubated under agitation for $1 \mathrm{hr}$ at $24^{\circ} \mathrm{C}$. Sepharose beads then were washed three times with $0.1 \mathrm{M}$ borate, $\mathrm{pH} 9.0$, and antibodies were coupled covalently to protein $\mathrm{A}$ by the addition of solid dimethylpimelimidate to a final concentration of $20 \mathrm{mM}$ and shaking for 30 $\mathrm{min}$ at $25^{\circ} \mathrm{C}$. Coupling was terminated by a brief wash and a 2-hr incubation with $1 \mathrm{M}$ Tris- $\mathrm{HCl}, \mathrm{pH} 7.5$.

\section{Immunoprecipitations}

Chloroplasts were lysed by resuspending them repeatedly with a syringe in lysis buffer $(0.1 \%$ Triton X-100, $20 \mathrm{mM} 3$-[N-morpholino]propanesulfonic acid [Mops]-KOH, pH 7.4, $154 \mathrm{mM} \mathrm{NaCl}, 250 \mathrm{mM}$ sucrose, $5 \mathrm{mM}$ EDTA, $0.1 \mathrm{mM}$ phenylmethylsulfonyl fluoride [PMSF],
$0.5 \mathrm{mM} \varepsilon$-aminocaproic acid, and $0.1 \mathrm{mM}$ benzamidine) and soluble proteins were recovered after a 20 -min centrifugation at $30,000 \mathrm{~g}$ in a $\mathrm{JA}-20$ rotor (Beckman) at $4^{\circ} \mathrm{C}$. For the immunoprecipitation of CGE1 for electrospray ionization mass spectrometry (ESI-MS), whole cells were lysed by sonication in lysis buffer lacking sucrose and soluble proteins were separated from membranes by a 30-min centrifugation on a $0.6 \mathrm{M}$ sucrose cushion in a SW-41 rotor at $300,000 \mathrm{~g} \mathrm{rpm}$ and $4^{\circ} \mathrm{C}$.

Protein A-Sepharose beads with coupled antibodies were equilibrated in lysis buffer and incubated under agitation with soluble proteins for $1.5 \mathrm{hr}$ at $4^{\circ} \mathrm{C}$. Beads were washed four times with $1.4 \mathrm{~mL}$ of lysis buffer and once with $1 \mathrm{~mL}$ of $10 \mathrm{mM}$ Tris- $\mathrm{HCl}, \mathrm{pH} 7.5$. Bound proteins were eluted either by boiling after the addition of 1 volume of $2 \times$ nonreducing sample buffer ( $125 \mathrm{mM}$ Tris, $\mathrm{pH} 6.8,20 \%$ glycerol, $4 \%$ SDS, and $0.005 \%$ bromophenyl blue), or by incubation with elution buffer (20 mM Mops-KOH, pH 7.4, $80 \mathrm{mM} \mathrm{KCl,} 2.5 \mathrm{mM} \mathrm{MgCl}_{2}$, and nucleotide triphosphates) for $15 \mathrm{~min}$ at $24^{\circ} \mathrm{C}$. In the latter case, eluted proteins were precipitated with trichloroacetic acid at a final concentration of $16 \%$, pelleted by centrifugation, washed twice in $100 \%$ acetone, resuspended in $1 \times$ nonreducing sample buffer, and boiled.

\section{Colorless Native PAGE}

Concentrated Chlamydomonas cells were sonicated in a buffer containing $50 \mathrm{mM}$ Bis-Tris- $\mathrm{HCl}, \mathrm{pH}$ 7.0, $0.5 \mathrm{M} \varepsilon$-aminocaproic acid, $15 \%$ glycerol, $1 \mathrm{mM} \mathrm{MgCl}, 10 \mathrm{mM} \mathrm{KCl}, 100 \mu \mathrm{M}$ PMSF, 0.004\% Ponceau $\mathrm{S}$, and either $1 \mathrm{mM}$ ATP or 2 units $/ \mathrm{mL}$ apyrase. The lysate was centrifuged in a TL-100 rotor (Beckman) for $15 \mathrm{~min}$ at $540,000 \mathrm{~g}$ and $4^{\circ} \mathrm{C}$. Soluble proteins were separated on a 6 to $18 \%$ colorless native polyacrylamide gel (Schägger et al., 1994) at $250 \mathrm{~V}$ for $14 \mathrm{hr}$ and at $500 \mathrm{~V}$ for the remainder of the run. For the second-dimension run, a gel slice of the first dimension was incubated in $1 \%$ SDS, $0.01 \mathrm{M} \mathrm{DTT}$, and $0.1 \mathrm{M} \mathrm{Na}_{2} \mathrm{CO}_{3}$ for $15 \mathrm{~min}$ at $65^{\circ} \mathrm{C}$ and washed extensively with cathode buffer (Laemmli, 1970). The gel slice then was cast into a stacking gel and proteins were separated by 7.5 to $15 \%$ SDS-PAGE.

\section{SDS-PAGE}

SDS-PAGE was performed according to Laemmli (1970). Protein concentrations were determined with amido black (Popov et al., 1975). Proteins were visualized by staining with silver nitrate or Coomassie Brilliant Blue R 250 or transferred to nitrocellulose membranes (Hybond C-super; Amersham-Pharmacia, Buckinghamshire, UK) by semidry blotting using a discontinuous transfer system. For microsequencing, proteins were transferred to polyvinylidene difluoride (PVDF) membranes (Millipore, Bedford, MA) with a transfer buffer containing $10 \%$ methanol and $10 \mathrm{mM}$ cyclohexylaminopropane sulfonic acid, $\mathrm{pH} 11$. Immunodetection was performed with 125/-labeled protein A or enhanced chemiluminescence (AmershamPharmacia). Radioactive signals were quantified by phosphorimaging (Molecular Dynamics, Sunnyvale, CA).

\section{Nucleic Acid Manipulations}

The sequence coding for the mature CGE1 protein was subcloned after amplification with polymerase chain reaction (PCR) from a $\lambda$-ZAP (Stratagene) cDNA library (kindly provided by V. Kurvari, University of Texas, Dallas) with the following cycle: $5 \mathrm{~min}$ at $95^{\circ} \mathrm{C}, 40$ repetitions 
of $1 \mathrm{~min}$ at $94^{\circ} \mathrm{C}, 1 \mathrm{~min}$ at $64^{\circ} \mathrm{C}, 2 \mathrm{~min}$ at $74^{\circ} \mathrm{C}$, and $5 \mathrm{~min}$ at $74^{\circ} \mathrm{C}$. Primers $5^{\prime}$-aaggatccatgGCGGCTGAGGTACAGGAGGCCGA-3' and 5'-ttgggtaaccCTCCTCAGAGCTAGCCGCAGGGCCGT-3' (CGE1 coding regions are in uppercase letters) were deduced from CGE1 expressed sequence tags (ESTs). Complete cDNA clones were obtained from the same cDNA library by hybridization with the radiolabeled CGE1 coding sequence as described previously (Schroda et al., 1999).

Total Chlamydomonas DNA was isolated by incubating cells in $2 \%$ cetyltrimethyl ammonium bromide, $100 \mathrm{mM}$ Tris- $\mathrm{HCl}, \mathrm{pH} 8.0,20 \mathrm{mM}$ EDTA, and $1.4 \mathrm{M} \mathrm{NaCl}$ for $1 \mathrm{hr}$ at $65^{\circ} \mathrm{C}$ followed by one phenol/ chloroform and one chloroform extraction. Nucleic acids were precipitated with isopropanol and resuspended in Tris-EDTA (TE) buffer supplemented with RNase A. Total RNA was prepared according to Kropat et al. (1997). DNA and RNA gel blot analyses were performed using standard methods (Sambrook et al., 1989), and hybridizations were according to Schroda et al. (1999).

Reverse transcription was conducted on $50 \mu \mathrm{g}$ of total RNA using Moloney murine leukemia virus reverse transcriptase (United States Biochemical Corp.) according to the manufacturer's instructions. Subsequent PCR amplification was performed in the presence of $0.25 \mu \mathrm{Ci}$ of ${ }^{33} \mathrm{P}-\mathrm{dATP}$ (Amersham-Pharmacia) with the cycle described above but with an annealing temperature of $53^{\circ} \mathrm{C}$. PCR products were separated on a native $1 \times$ Tris-borate/EDTA (TBE) polyacrylamide gel for 27 $\mathrm{hr}$ at $66 \mathrm{~V}$ according to Sambrook et al. (1989).

\section{Purification of HSP70B and CGE1 Proteins and Generation of Antisera}

Sequences coding for the mature HSP70B and CGE1 proteins including $\mathrm{N}$ - and $\mathrm{C}$-terminal hexahistidine tags were cloned into $\mathrm{PQE}$ vectors (Qiagen, Hilden, Germany). Recombinant proteins were overexpressed in Escherichia coli and purified using nickel-nitrilotriacetic acid agarose according to the protocol of the manufacturer (Qiagen, Hilden, Germany). Rabbit CGE1 antiserum was raised against the denatured protein by Neosystem (Strasbourg, France).

\section{Electrospray lonization Mass Spectrometry ESI-MS}

SDS-PAGE and protein gel blotting to PVDF was as described above. The blot was stained with $0.1 \%$ Coomassie Brilliant Blue $\mathrm{R}$ 250 , and the band corresponding to CGE1 was excised. Protein was displaced from the PVDF membrane in a solution of $2 \%$ SDS, $1 \%$ Triton $\mathrm{X}-100$, and $50 \mathrm{mM}$ Tris, $\mathrm{pH}$ 9.0, for $16 \mathrm{hr}$ at room temperature with gentle agitation and frozen at $-80^{\circ} \mathrm{C}$ for shipping. The protein was precipitated with chloroform/methanol (Wessel and Flügge, 1984), and the pellet was air dried for $2 \mathrm{~min}$ before dissolution in $50 \mu \mathrm{L}$ of $60 \%$ formic acid and size exclusion chromatography mass spectrometry. Size exclusion chromatography mass spectrometry was performed using a Super SW2000 column $(4.6 \times 300 \mathrm{~mm}$; Tosohaas, Montgomeryville, $\mathrm{PA})$ in chloroform $/$ methanol $/ 1 \%$ formic acid in water $(4: 4: 1, \mathrm{v} / \mathrm{v})$ at $40^{\circ} \mathrm{C}$ with a flow rate of $250 \mu \mathrm{L} / \mathrm{min}$ that was coupled to the ion spray source of an API III triple quadrupole mass spectrometer (Sciex, Thornhill, Canada) as described (Whitelegge et al., 1999).

\section{Accession Numbers}

The GenBank accession numbers for the sequences described in this article are AF406935 (CGE1a) and AF406936 (CGE1b).

\section{ACKNOWLEDGMENTS}

We thank Satoshi Tabata for providing plasmid AV391963, Bernd Bukau for antibodies against DnaK and GrpE, Olivier Deloche, Debbie Ang, and Costa Georgopoulos for strains OD212, DA15, and DA16, and Bodo Rak for phage $\lambda$. This work was supported by the Centre National de la Recherche Scientifique, by a grant of the Deutsche Forschungsgemeinschaft to C.F.B, and by a fellowship of the Hochschulsonderprogramm III via the Deutscher Akademischer Austauschdienst to M.S.

Received May 22, 2001; accepted September 13, 2001.

\section{REFERENCES}

Ang, D., Chandrasekhar, G.N., Zylicz, M., and Georgopoulos, C. (1986). Escherichia coli grpE gene codes for heat shock protein B25.3, essential for both $\lambda$ DNA replication at all temperatures and host growth at high temperatures. J. Bacteriol. 167, 25-29.

Asamizu, E., Nakamura, Y., Sato, S., Fukuzawa, H., and Tabata, S. (1999). A large scale structural analysis of cDNAs in a unicellular green alga, Chlamydomonas reinhardtii: Generation of 3433 non-redundant expressed sequence tags. DNA Res. 6, 369-373.

Azem, A., Oppliger, W., Lustig, A., Jenö, P., Feifel, B., Schatz, G., and Horst, M. (1997). The mitochondrial hsp70 chaperone system: Effect of adenine nucleotides, peptide substrate, and mGrpE on the oligomeric state of mhsp70. J. Biol. Chem. 272, 20901-20906.

Ballinger, C.A., Connell, P., Wu, Y., Hu, Z., Thompson, L.J., Yin, L.-Y., and Patterson, C. (1999). Identification of CHIP, a novel tetratricopeptide repeat-containing protein that interacts with heat shock proteins and negatively regulates chaperone functions. Mol. Cell. Biol. 19, 4535-4545.

Beckmann, R.P., Mizzen, L.A., and Welch, W.J. (1990). Interaction of Hsp 70 with newly synthesized proteins: Implications for protein folding and assembly. Science $248,850-854$.

Bolliger, L., Deloche, O., Glick, B.S., Georgopoulos, C., Jenö, P., Kronidou, N., Horst, M., Morishima, N., and Schatz, G. (1994). A mitochondrial homolog of bacterial GrpE interacts with mitochondrial hsp70 and is essential for viability. EMBO J. 13, 19982006.

Bonk, M., Tadros, M., Vandekerckhove, J., Al-Babili, S., and Beyer, P. (1996). Purification and characterization of chaperonin 60 and heat-shock protein 70 from chromoplasts of Narcissus pseudonarcissus. Plant Physiol. 111, 931-939.

Boston, R.S., Viitanen, P.V., and Vierling, E. (1996). Molecular chaperones and protein folding in plants. Plant Mol. Biol. 32, 191-222.

Buchberger, A., Schröder, H., Büttner, M., Valencia, A., and Bukau, B. (1994). A conserved loop in the ATPase domain of the DnaK chaperone is essential for stable binding of GrpE. Nat. Struct. Biol. 1, 95-101.

Bukau, B., and Horwich, A.L. (1998). The Hsp70 and Hsp60 chaperone machines. Cell 92, 351-366.

Deloche, O., and Georgopoulos, C. (1996). Purification and biochemical properties of Saccharomyces cerevisiae's Mge1p, the 
mitochondrial cochaperone of Ssc1p. J. Biol. Chem. 271, 2396023966.

Deloche, O., Kelley, W.L., and Georgopoulos, C. (1997). Structure-function analyses of the Ssc1p, Mdj1p, and Mge1p Saccharomyces cerevisiae mitochondrial proteins in Escherichia coli. J. Bacteriol. 179, 6066-6075.

Drzymalla, C., Schroda, M., and Beck, C.F. (1996). Light inducible gene $H S P 70 B$ encodes a chloroplast-localized heat shock protein in Chlamydomonas reinhardtii. Plant Mol. Biol. 31, 1185-1194.

Emanuelsson, O., Nielsen, H., and von Heijne, G. (1999). ChloroP, a neural network-based method for predicting chloroplast transit peptides and their cleavage sites. Protein Sci. 8, 978-984.

Franzén, L.-G., Rochaix, J.-D., and von Heijne, G. (1990). Chloroplast transit peptides from green alga Chlamydomonas share features with both mitochondrial and higher plant chloroplast presequences. FEBS Lett. 280, 165-168.

Gässler, C.S., Wiederkehr, T., Brehmer, D., Bukau, B., and Mayer, M.P. (2001). Bag-1M accelerates nucleotide release for human Hsc70 and Hsp70 and can act concentration dependent as positive and negative cofactor. J. Biol. Chem. 276, 3253832544.

Hamel, P., Olive, J., Pierre, Y., Wollman, F.-A., and de Vitry, C. (2000). A new subunit of cytochrome $b_{6} / f$ complex undergoes reversible phosphorylation upon state transition. J. Biol. Chem. 275, 17072-17079.

Harris, E.H. (1989). The Chlamydomonas Sourcebook: A Comprehensive Guide to Biology and Laboratory Use. (San Diego, CA: Academic Press).

Harrison, C.J., Hayer-Hartl, M., Di Liberto, M., Hartl, F.-U., and Kuriyan, J. (1997). Crystal structure of the nucleotide exchange factor GrpE bound to the ATPase domain of the molecular chaperone DnaK. Science 276, 431-435.

Hartl, F.-U. (1996). Molecular chaperones in cellular protein folding. Nature 381, 571-580.

Höhfeld, J., Minami, Y., and Hartl, F.-U. (1995). Hip, a novel cochaperone involved in the eukaryotic $\mathrm{Hsc} 70 / \mathrm{Hsp} 40$ reaction cycle. Cell 83, 589-598.

Horst, M., Oppliger, W., Rospert, S., Schonfeld, H.J., Schatz, G., and Azem, A. (1997). Sequential action of two hsp70 complexes during protein import into mitochondria. EMBO J. 16, 1842-1849.

Ikeda, E., Yoshida, S., Mitsuzawa, H., Uno, I., and Toh-e, A. (1994). YGE1 is a yeast homologue of Escherichia coli grpE and is required for maintenance of mitochondrial functions. FEBS Lett. 339, 265-268.

Ivey, R.A., III, and Bruce, B.D. (2000). In vivo and in vitro interaction of DnaK and a chloroplast transit peptide. Cell Stress Chaperones 5, 62-71.

Ivey, R.A., III, Subramanian, C., and Bruce, B.D. (2000). Identification of a Hsp70 recognition domain within the Rubisco small subunit transit peptide. Plant Physiol. 122, 1289-1299.

Jordan, R., and McMacken, R. (1995). Modulation of the ATPase activity of the molecular chaperone DnaK by peptides and the DnaJ and GrpE heat shock proteins. J. Biol. Chem. 270, 45634569.

Ko, K., Bornemisza, O., Kourtz, L., Ko, Z.W., Plaxton, W.C., and
Cashmore, A.R. (1992). Isolation and characterization of a cDNA clone encoding a cognate $70 \mathrm{kDa}$ heat shock protein of the chloroplast envelope. J. Biol. Chem. 267, 2986-2993.

Kourtz, L., and Ko, K. (1997). The early stage of chloroplast protein import involves Com70. J. Biol. Chem. 272, 2808-2813.

Kropat, J., Oster, U., Rüdiger, W., and Beck, C.F. (1997). Chlorophyll precursors are signals of chloroplast origin involved in light induction of nuclear heat-shock genes. Proc. Natl. Acad. Sci. USA 94, 14168-14172.

Laemmli, U.K. (1970). Cleavage of structural proteins during the assembly of the head of bacteriophage T4. Nature 227, 680-685.

Laloraya, S., Gambill, B.D., and Craig, E.A. (1994). A role for a eukaryotic GrpE-related protein, Mgep1, in protein translocation. Proc. Natl. Acad. Sci. USA 91, 6481-6485.

Liberek, K., Marszalek, J., Ang, D., Georgopoulos, C., and Zylicz, M. (1991). Escherichia coli DnaJ and GrpE heat shock proteins jointly stimulate ATPase activity of DnaK. Proc. Natl. Acad. Sci. USA 88, 2874-2878.

Madueño, F., Napier, J.A., and Gray, J.C. (1993). Newly imported iron-sulfur protein associates with both Cpn60 and Hsp70 in the chloroplast stroma. Plant Cell 5, 1865-1876.

Mally, A., and Witt, S.N. (2001). GrpE accelerates peptide binding and release from the high affinity state of DnaK. Nat. Struct. Biol. 8, 254-257.

Mamelak, D., and Lingwood, C. (2001). The ATPase domain of hsp70 possesses a unique binding specificity for 3 '-sulfogalactolipids. J. Biol. Chem. 276, 449-456.

Miao, B., Davis, J.E., and Craig, E.A. (1997). Mge1 functions as a nucleotide release factor for Ssc1, a mitochondrial hsp70 of Saccharomyces cerevisiae. J. Mol. Biol. 265, 541-552.

Miller, S.M., and Kirk, D.L. (1999). glsA, a Volvox gene required for asymmetric division and germ cell specification, encodes a chaperone-like protein. Development 126, 649-658.

Nakai, M., Kato, Y., Ikeda, E., Toh-e, A., and Endo, T. (1994). YGE1p, a eukaryotic GrpE homolog, is localized in the mitochondrial matrix and interacts with mitochondrial hsp70. Biochem. Biophys. Res. Commun. 200, 435-442.

Naylor, D.J., Hoogenraad, N.J., and Hoj, P.B. (1996). Isolation and characterization of a cDNA encoding rat mitochondrial GrpE, a stress-inducible nucleotide-exchange factor of ubiquitous appearance in mammalian organs. FEBS Lett. 396, 181-188.

Neidhardt, F.C., VanBogelen, R.A., and Vaughn, V. (1984). The genetics and regulation of heat-shock proteins. Annu. Rev. Genet. 18, 295-329.

Nimura, K., Yoshikawa, H., and Takahashi, H. (1996). DnaK3, one of the three DnaK proteins of cyanobacterium Synechococcus sp. PCC7942, is quantitatively detected in the thylakoid membrane. Biochem. Biophys. Res. Commun. 229, 334-340.

Oguchi, K., Nimura, K., Yoshikawa, H., and Takahashi, H. (1997) Sequence and analysis of a dnaJ homologue gene in cyanobacterium Synechococcus sp. PCC7942. Biochem. Biophys. Res. Commun. 236, 461-466.

Osipiuk, J., Georgopoulos, C., and Zylicz, M. (1993). Initiation of $\lambda$ DNA replication: The Escherichia coli small heat shock proteins, 
DnaJ and GrpE, increase DnaK's affinity for the $\lambda P$ protein. J. Biol. Chem. 268, 4821-4827.

Packschies, L., Theyssen, H., Buchberger, A., Bukau, B., Goody, R.S., and Reinstein, J. (1997). GrpE accelerates nucleotide exchange of the molecular chaperone DnaK with an associative displacement mechanism. Biochemistry 36, 3417-3422.

Padidam, M., Reddy, V.S., Beachy, R.N., and Fauquet, C.M. (1999). Molecular characterization of a plant mitochondrial chaperone GrpE. Plant Mol. Biol. 39, 871-881.

Popov, N., Schmitt, S., and Matthies, H. (1975). Eine störungsfreie Mikromethode zur Bestimmung des Proteingehalts in Gewebshomogenaten. Acta Biol. Germ. 34, 1441-1446.

Rassow, J., Maarse, A.C., Krainer, E., Kübrich, M., Müller, H., Meijer, M., Craig, E.A., and Pfanner, N. (1994). Mitochondrial protein import: Biochemical and genetic evidence for interaction of matrix hsp70 and the inner membrane protein MIM44. J. Cell Biol. 127, 1547-1556.

Rial, D.V., Arakaki, A.K., and Ceccarelli, E.A. (2000). Interaction of the targeting sequence of chloroplast precursors with Hsp70 molecular chaperones. Eur. J. Biochem. 267, 6239-6248.

Rüdiger, S., Germeroth, L., Schneider-Mergener, J., and Bukau, B. (1997). Substrate specificity of the DnaK chaperone determined by screening of cellulose-bound peptide libraries. EMBO J. 16, 1501-1507.

Sambrook, J., Fritsch, E.F., and Maniatis, T. (1989). Molecular Cloning: A Laboratory Manual. (Cold Spring Harbor, NY: Cold Spring Harbor Laboratory Press).

Schägger, H., Cramer, W.A., and von Jagow, G. (1994). Analysis of molecular masses and oligomeric states of protein complexes by blue native electrophoresis and isolation of membrane protein complexes by two-dimensional native electrophoresis. Anal. Biochem. 217, 220-230.

Schleiff, E., and Soll, J. (2000). Travelling of proteins through membranes: Translocation into chloroplasts. Planta 211, 449-456.

Schlicher, T., and Soll, J. (1997). Chloroplastic isoforms of DnaJ and GrpE in pea. Plant Mol. Biol. 33, 181-185.

Schnell, D.J., Kessler, F., and Blobel, G. (1994). Isolation of components of the chloroplast protein import machinery. Science 266, 1007-1012.

Schönfeld, H.-J., Schmidt, D., Schröder, H., and Bukau, B. (1995). The DnaK chaperone system of Escherichia coli: Quaternary structures and interactions of the DnaK and GrpE components. J. Biol. Chem. 270, 2183-2189.

Schroda, M., Vallon, O., Wollman, F.-A., and Beck, C.F. (1999). A chloroplast-targeted heat shock protein 70 (HSP70) contributes to the photoprotection and repair of photosystem II during and after photoinhibition. Plant Cell 11, 1165-1178.

Silflow, C.D. (1998). Organization of the nuclear genome. In Molecular Biology of Chlamydomonas: Chloroplasts and Mitochondria, J.-D. Rochaix, M. Goldschmidt-Clermont, and S. Merchant, eds (Dordrecht, The Netherlands: Kluwer Academic Publishers), pp. 25-40.

Soellick, T., Uhrig, J.F., Bucher, G.L., Kellmann, J.W., and Schreier, P.H. (2000). The movement protein NSm of tomato spotted wilt tospovirus (TSWV): RNA binding, interaction with the TSWV N protein, and identification of interacting plant proteins. Proc. Natl. Acad. Sci. USA 97, 2373-2378.

Szabo, A., Langer, T., Schröder, H., Flanagan, J., Bukau, B., and Hartl, F.-U. (1994). The ATP hydrolysis-dependent reaction cycle of the Escherichia coli Hsp70 system: DnaK, DnaJ, and GrpE. Proc. Natl. Acad. Sci. USA 91, 10345-10349.

Tsugeki, R., and Nishimura, M. (1993). Interaction of homologues of Hsp70 and Cpn60 with ferredoxin-NADP ${ }^{+}$reductase upon its import into chloroplasts. FEBS Lett. 320, 198-202.

von Gromoff, E.D., Treier, U., and Beck, C.F. (1989). Three lightinducible heat shock genes of Chlamydomonas reinhardtii. Mol. Cell. Biol. 9, 3911-3918.

Voos, W., Gambill, B.D., Laloraya, S., Ang, D., Craig, E.A., and Pfanner, N. (1994). Mitochondrial GrpE is present in a complex with hsp70 and preproteins in transit across membranes. Mol. Cell. Biol. 14, 6627-6634.

Wall, D., Zylicz, M., and Georgopoulos, C. (1994). The $\mathrm{NH}_{2}$-terminal 108 amino acids of the Escherichia coli DnaJ protein stimulate the ATPase activity of DnaK and are sufficient for $\lambda$ replication. J. Biol. Chem. 269, 5446-5451.

Wessel, D., and Flügge, U.-I. (1984). A method for the quantitative recovery of protein in dilute solution in the presence of detergents and lipids. Anal. Biochem. 138, 141-143.

Whitelegge, J.P., le Coutre, J., Lee, J.C., Engel, C.K., Privé, G.G., Faull, K.F., and Kaback, H.R. (1999). Towards the bilayer proteome, electrospray-ionization mass spectrometry of large intact transmembrane proteins. Proc. Natl. Acad. Sci. USA 96, 1069510698.

Wu, B., Ang, D., Snavely, M., and Georgopoulos, C. (1994). Isolation and characterization of point mutations in the Escherichia coli grpE heat shock gene. J. Bacteriol. 176, 6965-6973.

Wu, B., Wawrzynow, A., Zylicz, M., and Georgopoulos, C. (1996). Structure-function analysis of the Escherichia coli GrpE heat shock protein. EMBO J. 15, 4806-4816.

Zylicz, M., Ang, D., and Georgopoulos, C. (1987). The grpE protein of Escherichia coli: Purification and properties. J. Biol. Chem. 262, 17437-17442. 